\title{
Comparison of the effects of three types of heating tobacco system and conventional cigarettes on indoor air quality
}

\author{
Yoshihiro Enomoto $^{1}$ (D) $\cdot$ Ryosuke Imai $^{1} \cdot$ Keiko Nanjo $^{1} \cdot$ Yuichi Fukai $^{1} \cdot$ Katsura Ishikawa $^{2} \cdot$ Misato Kotaki $^{2}$
}

Received: 19 August 2021 / Accepted: 22 November 2021

Published online: 07 December 2021

(c) The Author(s) 2021 OPEN

\begin{abstract}
Environmental tobacco smoke (ETS) from conventional cigarettes is reported to affect indoor air quality (IAQ) in various real indoor environments. Recently, Japan Tobacco Inc. introduced three types of tobacco product that are heated rather than combusted. These comprise one direct heating tobacco system and two in-direct heating tobacco systems. In this study, the impact of using these products on IAQ was evaluated in an environmentally controlled chamber. Two environmental conditions, simulating restaurant and residential spaces, were examined. Under the same conditions, cigarette smoking and the presence of people only were used as positive and negative controls, respectively. The indoor air concentrations of 48 constituents (tobacco-specific nitrosamines, carbonyls, volatile organic compounds, total volatile organic compounds, polycyclic aromatic hydrocarbon, polycyclic aromatic amines, mercury, metals, ETS markers, propylene glycol, glycerol, carbon monoxide, carbon dioxide, suspended particle matter, ammonia, and nitrogen oxides) were measured. Compared with the presence of people, the concentrations of some constituents were actually increased when using heating tobacco products under both environmental conditions, simulating restaurant and residential spaces. However, the constituent concentrations were lower than those obtained by cigarette smoking, except for propylene glycol and glycerol, and below the exposure limits for constituents in air, as defined by air quality guidelines or regulations. Based on these data, the use of heating tobacco systems in appropriate indoor environments has less impacts compared to conventional cigarettes.
\end{abstract}

\section{Article Highlights}

- We measured the indoor air concentrations of chemical constituents generated when using three heating tobacco systems with different heating mechanisms in two environment conditions simulating restaurant and residential spaces (positive control: when smoking cigarettes, negative control: the presence of people only).

- In the measurement and analysis method used this study, it was possible to find not only that the air con- centration generated when using the heating tobacco systems in this study were considerably lower than that when smoking cigarettes, but also the differences of the concentrations between heating tobacco systems with different heating mechanisms.

- We showed some constituents which actually increased the air concentrations when using heating tobacco systems compared with the presence of people only.

Supplementary Information The online version contains supplementary material available at https://doi.org/10.1007/s42452-02104896-8.

$\triangle$ Yoshihiro Enomoto, yoshihiro.enomoto@jt.com | ${ }^{1}$ Scientific Product Assessment Center, Japan Tobacco Inc., 6-2 Umegaoka, Aoba-ku, Yokohama-City, Kanagawa 227-8512, Japan. ${ }^{2}$ Corporate, Scientific and Regulatory Affairs Division, Tobacco Business Headquarters, Japan Tobacco Inc., Kamiyacho Trust Tower, 4-1-1, Tranomon, Minato-ku, Tokyo 105-6927, Japan.

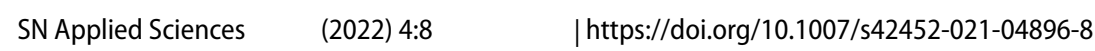


Keywords Indoor air quality (IAQ) · Heating tobacco system · Cigarette · Environmental tobacco smoke (ETS) · Simulated environmentally chamber

\section{Introduction}

Over the past decade, novel types of tobacco products such as heated tobacco products, heating tobacco systems and electronic cigarettes (e-cigarettes) have been launched.

In recent years, three types of heating tobacco systems have been introduced onto the market by Japan Tobacco Inc. as alternative to traditional tobacco products (In-direct heating Tobacco System Platform 1 Generation 0 version a (IT1.0a), In-direct heating Tobacco System Platform 2 Generation 0 version a (IT2.0a), and Direct heating Tobacco System Platform 2 Generation 2 version a (DT2.2a)) (Fig. 1). These products, unlike e-cigarettes, contain tobacco and create a tobacco enriched aerosol that can be inhaled. The tobacco is not combusted during the use of these systems. These products have different heating systems, and can be roughly classified as indirect and direct heating types. In-direct heating tobacco systems (IT systems) are composed of a puff activated electrical heating device with a battery, a cartridge containing nicotine free liquid, and a tobacco capsule containing tobacco granules. IT systems generate a thermally vaporized aerosol, which then passes through the tobacco capsule, with in capsule temperatures of approximately $30^{\circ} \mathrm{C}$ (IT1.0a) or $40^{\circ} \mathrm{C}$ (IT2.0a), before being inhaled. Evaporated tobacco derived flavors and nicotine are thus infused into the aerosol (Fig. 1a, b). This mechanism of tobacco aerosol generation differs from
Fig. 1 Schematic of three types of heating tobacco system: a IT1.0a, b IT2.0a, and c DT2.2a

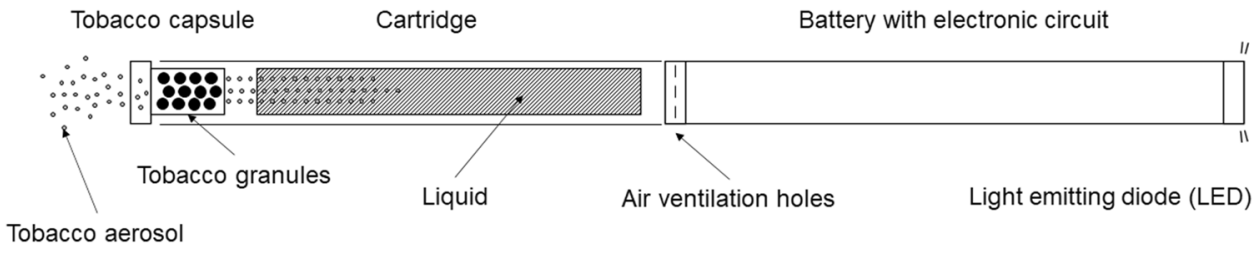

(a)

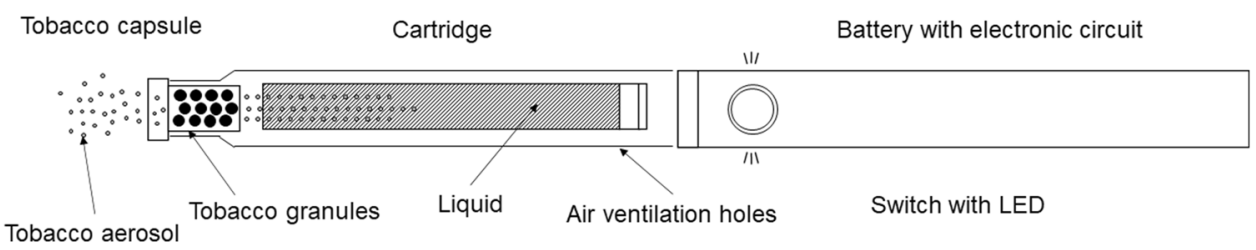

(b)

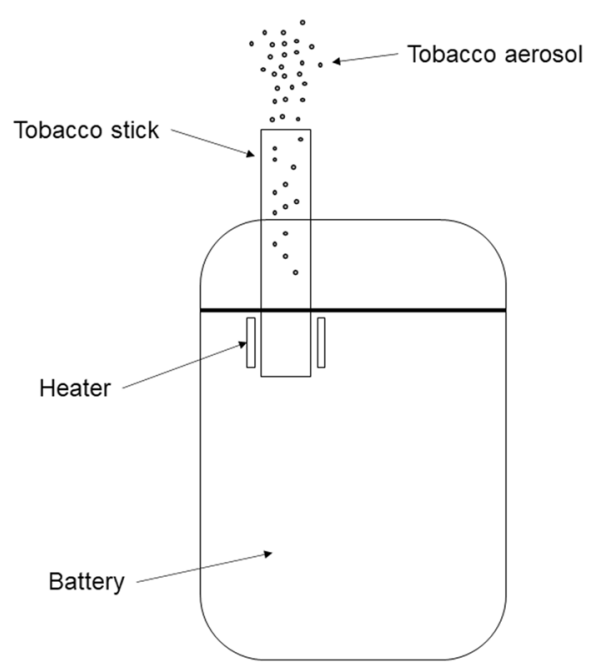

(c) 
most existing heated tobacco products in that it does not heat the tobacco directly during use. Instead, the tobacco is indirectly warmed by the aerosol passing through it. The IT systems differ from most e-cigarettes in that the carrier liquid does not contain nicotine. In contrast, direct heating tobacco systems (DT systems) heat tobacco leaf sticks directly using a heater, with the stick temperatures reaching approximately $200^{\circ} \mathrm{C}$ during use (Fig. 1C).

Environmental tobacco smoke (ETS) consists of mainstream smoke exhaled by smokers and side-stream smoke expelled from the tobacco, and is diffused and diluted in the air. ETS can affect indoor air quality (IAQ) and has been widely investigated in various real indoor environments [1-3].

Previous studies have investigated the impact of novel types of tobacco products on IAQ by measuring indoor air pollutants, such as ETS markers and tobacco constituents of concern to health [4-16]. However, most of these studies, including our previous study [10], have measured and evaluated a limited number of the indoor air concentrations of constituents.

In our previous study [10], we evaluated the IAQ during use of a Novel Tobacco Vapor (NTV, classified as an IT systems) product in simulated non-smoking area ("dining room" and "conference room") and smoking area ("smoking lounge") environments. A total of 18 constituents were measured in the air, ETS markers (respirable suspended particles (RSP), ultraviolet particulate matter (UVPM), fluorescent particulate matter (FPM), solanesol, nicotine, 3-ethenylpyridine), carbonyls (formaldehyde, acetaldehyde and acetone), a volatile organic compound (VOC; toluene), total volatile organic compounds (TVOC), NTV-specific constituents (propylene glycol, glycerol, and triacetin), carbon monoxide (CO), carbon dioxide $\left(\mathrm{CO}_{2}\right)$, ammonia, and suspended particle matter (SPM), were measured. All the measured constituents were either below the limit of quantification or at the same level as found in the chamber without NTV use, leading to the conclusion that the NTV product had no measurable effect on the IAQ in either simulated non-smoking or smoking areas [10].

Despite our previous study [10], more investigation is still required to enhance understanding of the impact of heating tobacco systems on the IAQ. It is necessary to measure more constituents that are of concern to health in mainstream and side-stream smoke and more ETS markers. It is also necessary to improve the detection sensitivity, because ETS consists of mainstream smoke exhaled by smokers and side-stream smoke expelled from the tobacco, and is diffused and diluted in the air.

The present study aimed to further measure and evaluate IAQ during the use of three heating tobacco systems and smoking tobacco cigarettes. A total of 48 constituents were measured in the air, tobacco-specific nitrosamines
(TSNA; nitrosonornicotine (NNN), nitrosoanatabine (NAT), nitrosoanabasine (NAB), and 4-( $N$-nitrosomethylamino)-1(3-pyridyl)-1-butanone (NNK)), carbonyls (formaldehyde, acetaldehyde, acetone, acrolein, propionaldehyde, crotonaldehyde, methyl ethyl ketone (MEK), and $n$-butyraldehyde), VOC (1,3-butadiene, isoprene, acrylonitrile, benzene, toluene, pyridine, and styrene), TVOC, a polycyclic aromatic hydrocarbons (PAH; benz[a]pyrene), polycyclic aromatic amines (PAA; 1-aminonaphthalene, 2-aminonaphthalene, 3-aminobiphenyl, and 4-aminobiphenyl), mercury, metals (lead, cadmium, chromium, nickel, beryllium, and arsenic), ETS markers (nicotine, 3-ethenylpyridine, RSP, UVPM, FPM, and solanesol), heating tobacco systemspecific constituents (propylene glycol and glycerol), $\mathrm{CO}$, $\mathrm{CO}_{2}$, online measurement of SPM (using piezobalance and light scattering), ammonia, and nitrogen oxides $\left(\mathrm{NO}_{x} ;\right.$ nitrogen oxide (NO), nitrogen dioxide $\left(\mathrm{NO}_{2}\right)$, and combined nitrogen oxides $\left(\mathrm{NO}+\mathrm{NO}_{2}\right)$ ). The constituents in the air investigated in this study included 33 of the 42 constituents recommended for reductions owing to the health risks, by Canadian public health authorities [17], ETS markers, and IAQ markers. The analysis of TSNA, carbonyls (acrolein, propionaldehyde, crotonaldehyde, MEK, and n-butyraldehyde), VOC (1,3-butadiene, isoprene, acrylonitrile, benzene, pyridine, and styrene), PAH, PAA, mercury, metals and $\mathrm{NO}_{\mathrm{x}}$ was added, and the detection sensitivity of the measurement of carbonyls (formaldehyde, acetaldehyde and acetone), a VOC (toluene), ETS markers (nicotine and 3-ethenylpyridine), propylene glycol and glycerol was improved, compared with our previous study [10]. This study was conducted in an environmentally controlled chamber simulating restaurant and residential spaces to assess substantially elevated concentrations of constituents, considering their detection in mainstream emission analysis.

\section{Materials and methods}

\subsection{Test products}

Three types of heating tobacco systems (IT1.0a, IT2.0a, and DT2.2a) and a commercial cigarette (Tar, 6 mg; nicotine, $0.5 \mathrm{mg}$; regular taste) were used in this study. Details of the heating tobacco systems are shown in Fig. 1. IT1.0a and IT2.0a are composed of three parts (tobacco capsule, cartridge, and battery). The tobacco capsule is inserted into the open end of the cartridge and then the cartridge is connected to the battery. IT1.0a is a low-temperature heating product that generates tobacco aerosol by heating the liquid in the cartridge and passing it through a tobacco capsule at approximately $30^{\circ} \mathrm{C}$. IAQ evaluations of IT1.0a have been reported in our previous study [10]. 
IT2.0a is also a low-temperature heating product, but the temperature of the tobacco capsule when tobacco aerosol is passed through it is approximately $40{ }^{\circ} \mathrm{C}$. The IT1.0a or IT2.0a can use five tobacco capsules (one cartridge) on a full battery charge. One tobacco capsule provides for approximately 50 puffs, although the number of puffs will vary depending on how deeply inhales. DT2.2a is composed of two parts (a tobacco stick and a battery with heater). The tobacco stick is inserted into the battery outlet. DT2.2a is a high-temperature heating product, meaning that the tobacco stick is heated directly and electronically to generate an aerosol containing nicotine and flavors. The temperature of the stick when the tobacco aerosol is passed through it is approximately $200{ }^{\circ} \mathrm{C}$. The tobacco capsules and sticks used had a regular taste (nonmenthol). A commercial cigarette sold on the Japanese market was used as a reference, which had the following specifications: Tar, $6 \mathrm{mg}$; nicotine, $0.5 \mathrm{mg}$; regular taste (no menthol added); total length, $84 \mathrm{~mm}$ including filter (cellulose acetate filter and charcoal filter).

\subsection{Mainstream emissions}

Collection and analysis of chemical constituents in mainstream emissions were conducted at Labstat International ULC (Labstat; Kitchener, Ontario, Canada). The heating tobacco systems and cigarette were puffed according to International Organization for Standardization (ISO) standards 3308:2012 [18], 3402:1999 [19], and 4387:2000 [20]. Mainstream constituents were selected according to the Health Canada reporting requirement [17], as follows: Total particulate matter (TPM), nicotine, carbon monoxide (CO), water, tobacco-specific nitrosamines (TSNA; $\mathrm{N}$-nitrosonornicotine, NNN; $N$-nitrosoanatabine, NAT; $N$-nitrosoanabasine, NAB; and 4-(N-nitrosomethylamino)-1-(3-pyridyl)-1butanone, NNK), carbonyls (formaldehyde, acetaldehyde, acetone, acrolein, propionaldehyde, crotonaldehyde, methyl ethyl ketone, and butyraldehyde), volatile organic compounds (volatiles; 1,3-butadiene, isoprene, acrylonitrile, benzene, and toluene), semi-volatiles (pyridine, quinoline, styrene), polycyclic aromatic hydrocarbon (PAH) benzo[a]pyrene (BaP), polycyclic aromatic amines (PAA; 1-aminonaphthalene, 2-aminonaphthalene, 3-aminobiphenyl, and 4-aminobiphenyl), mercury $(\mathrm{Hg})$, metals (lead $(\mathrm{Pb})$, cadmium $(\mathrm{Cd})$, chromium $(\mathrm{Cr})$, nickel $(\mathrm{Ni})$, arsenic $(\mathrm{As})$, and selenium (Se)), ammonia $\left(\mathrm{NH}_{3}\right)$, nitrogen oxides ( $\mathrm{NO}$ and NOx), phenolic compounds (PHE; hydroquinone, resorcinol, catechol, phenol, $o$-cresol, $m$-cresol, and $p$-cresol), and hydrogen cyanide ( $\mathrm{HCN})$. Nicotine-free dry particulate matter (NFDPM)/tar was calculated using the equation NFDPM/tar (mg) =TPM (mg) - nicotine (mg) - water (mg)". In the heating tobacco system tests, new tobacco capsules and cartridges were used for each aerosol collection. Five replicates were collected for mainstream testing.

\subsection{Environmentally controlled chamber}

The layout of the environmentally controlled chamber is shown in Fig. 2. The chamber had a floor size of $8.32 \mathrm{~m}^{2}$ and volume of $16.64 \mathrm{~m}^{3}$ (width, $3.2 \mathrm{~m}$; depth, $2.6 \mathrm{~m}$; height, $2.0 \mathrm{~m}$ ) with a stainless-steel inner wall, electric lights, an electric fan, a window, and a door. An electric fan, with rotational body, was suspended from the chamber ceiling and was running throughout testing to disperse the aerosol or cigarette smoke and obtain a uniform air concentration in the chamber. Outside air was filtered through a high-efficiency particulate air (HEPA) filter and introduced into the chamber as supply air through an air supply opening in the ceiling. Both temperature and relative humidity were monitored outside the chamber. Three sampling points (SP) were used to measure air quality. When testing, outside and inside air were continuously sampled at $\mathrm{SP}_{\text {outside, }} \mathrm{SP}_{\text {supply' }}$ and $\mathrm{SP}_{\text {exhaust' }}$ as shown in Fig. 2. Regarding the sampling points, the aerosol uniformity test for our environmentally controlled chamber were measured at four points (Supplementary Fig. S1), SP1 (the same position of $\left.\mathrm{SP}_{\text {exhaust }}\right), \mathrm{SP} 2, \mathrm{SP} 3$ and SP4, to confirm the spatial and temporal uniformity under conditions simulating "Restaurant" and "Residential" environments. Based on the online traces (Supplementary Fig. S2-S3) and the average of indoor air concentrations (Supplementary Table S1) of $\mathrm{CO}$ and SPM, the aerosol uniformity under chamber conditions in this study was considered to be acceptable. To confirm the average concentration in the chamber, constituents were sampled at $\mathrm{SP}_{\text {exhaust }}$ and to check background contamination, constituents were sampled at $\mathrm{SP}_{\text {outside, }}$ except for SPM. SPM was sampled at SP suppply . The concentrations $(\mathrm{C})$ at $\mathrm{SP}_{\text {outside, }} \mathrm{SP}_{\text {supplyr }}$ and $\mathrm{SP}_{\text {exhaust }}$ corresponded to the background $\left(\mathrm{C}_{\mathrm{BG}}\right)$ and exhaust $\left(\mathrm{C}_{\text {exhaust }}\right)$ concentrations.

\subsection{Environmental simulations for IAQ evaluation in the chamber}

In this study, the concentration of indoor air constituents in the chamber was measured when heating tobacco systems (IT1.0a, IT2.0a, and DT2.2a) and a cigarette were used under conditions simulating "Restaurant" and "Residential" environments. The ventilation rate of each set of conditions ("Restaurant", $108 \mathrm{~m}^{3} / \mathrm{h}, 6.5$ air changes/h; "Residential", $18 \mathrm{~m}^{3} / \mathrm{h}, 1.1$ air changes/h) was based on European ventilation performance standard BS EN 15,251 [21]. These environmental simulations are summarized in Table 1. The cigarette consumption rate (cigarettes/h) was rounded up to the next integer 
(a)

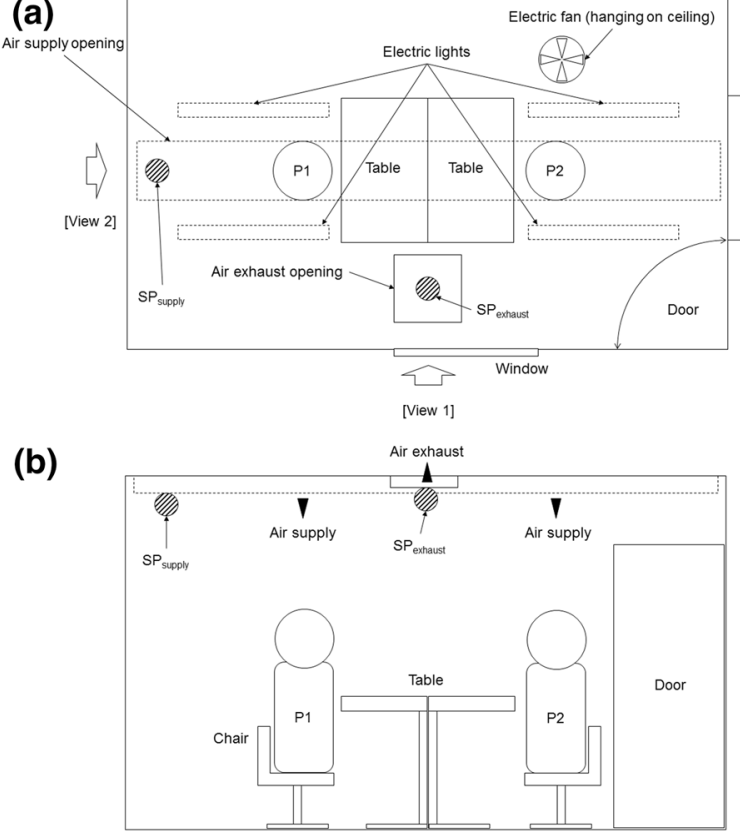

Fig. 2 Layout of environmentally controlled chamber: a Layout of "Restaurant" conditions (view from ceiling); b side view of "Restaurant" conditions (view from [view 1] in a); c side view of "Restaurant" (c)

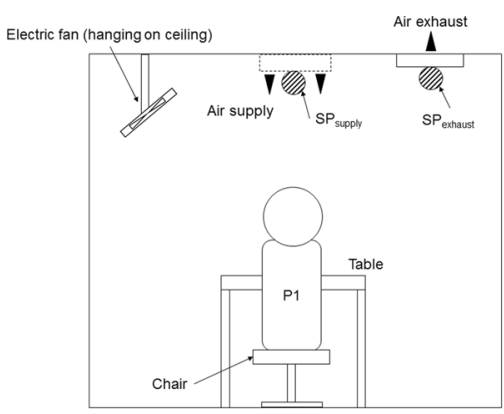

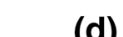

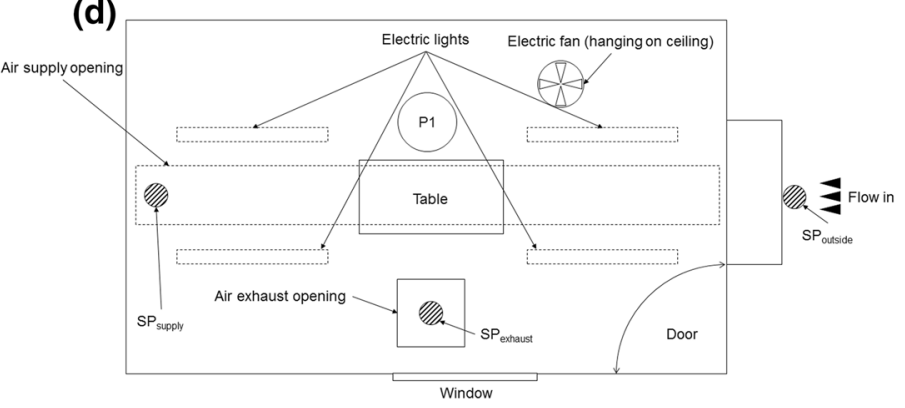

conditions (view from [view 2] in a); d layout of "Residential" conditions (view from ceiling)
Table 1 Experimental simulations for this IAQ study

\begin{tabular}{llll}
\hline $\begin{array}{l}\text { Condition } \\
\text { Standard }\end{array}$ & & $\begin{array}{l}\text { "Restaurant" } \\
\text { EN15251-2007 Category III } \\
\text { non-low-polluted building }\end{array}$ & $\begin{array}{l}\text { "Residential" } \\
\text { EN15251- } \\
\text { 2007 Cat- } \\
\text { egory III }\end{array}$ \\
\hline Smokers number by reference $^{\mathrm{a}}$ & $\left(\right.$ Person $\left./ 8.32 \mathrm{~m}^{2}\right)$ & 5.55 & $1^{\mathrm{c}}$ \\
Actual smoker $_{\text {Calculated consumption }}$ & $\left(\right.$ Person $\left./ 8.32 \mathrm{~m}^{2}\right)$ & $2^{\mathrm{b}}$ & 1 \\
Actual consumption & $($ ClGARETTE $/ \mathrm{h})$ & 6.7 & 1.2 \\
Ventilation volume & $($ Cigarette $/ \mathrm{h})$ & 7 & 2 \\
Ventilation rate & $\left(\mathrm{m}^{3} / \mathrm{h}\right)$ & 108 & $18^{\mathrm{d}}$ \\
\hline
\end{tabular}

${ }^{\text {a }}$ Standard smoking rate is $20 \%$. As the rate in this study was considered to be higher than $20 \%, 100 \%$ was adopted

${ }^{\mathrm{b}}$ Actual smoker numbers are different from smoker numbers by reference. As the influence of chemical constituents derived from the human body is removed as much as possible and product usage per person is set to avoid being too high

'The number of persons is set based on the private area of $10 \mathrm{~m}^{2}$ per person in the Basic Plan for Living Life (national plan; formula, $10 \mathrm{~m}^{2} \times$ [number of households] $+10 \mathrm{~m}^{2}$ )

${ }^{d}$ Ventilation air volume set based on the "amount of outside air introduced into the living room or bedroom". Only the amount of air given per area is used. Ventilation air volume per person is not given because severe conditions are assumed 
to prevent underestimation. For example, a calculated cigarette consumption rate of 6.7 (cigarettes/h) by BS EN 15,251 was rounded up to 7 (Table 1).

\subsection{Procedure for IAQ measurement in the chamber}

The procedure for measuring the IAQ in the environmental chamber is described below. Air inside the chamber was ventilated at $400 \mathrm{~m}^{3} / \mathrm{h}$ for more than $40 \mathrm{~min}$ with the door closed. The ventilation rate inside the chamber was set to "Restaurant" or "Residential" when the $\mathrm{CO}_{2}$ concentration of the exhaust air inside the chamber was the same as that of the outside air. New tobacco capsules and cartridges for the heating tobacco systems were used in each IAQ experiment. Healthy adult smokers (in-house volunteers from whom informed consent was obtained) participated in this study. There were no restrictions on food and drink outside the survey hours and during breaks, but volunteers were restricted from using tobacco products other than surveyed products on all survey days.

Under "Restaurant" conditions, two smokers entered the chamber in each test and alternately smoked one cigarette every $8 \mathrm{~min}$, starting at $0 \mathrm{~min}$, throughout the test. The cigarette number or its equivalent was a total of seven (three or four/person). The number of puffs per cigarette of IT1.0a or IT2.0a was defined using the average number of puffs for various cigarette brands sold on the Japanese market. For the seven major brands in Japan, the average is 7.4 puffs per cigarette [22]. The number of puffs per cigarette for the test was set as double the average puff number and rounded up to 15 puffs per cigarette to avoid underestimation. The number of puffs per cigarette of DT2.2a was defined as the puff upper limit of the device (16 puffs per cigarette). When using the heating tobacco systems, the number of puffs (IT1.0a and IT2.0a: 15 puffs, DT2.2a: 16 puffs) and smoking time ( $8 \mathrm{~min}$ ) per cigarette were specified, but the timing of the puffs was arbitrary. When smoking the conventional cigarette, the smoking time (8 $\mathrm{min}$ ) per cigarette was specified, but the number of puffs per cigarette and the timing of the puffs were arbitrary.

Under "Residential" conditions, one smoker entered the chamber in each test. The smoker smoked one cigarette every $30 \mathrm{~min}$, starting at $0 \mathrm{~min}$, throughout the test. The cigarette number or its equivalent per person was two. The number of puffs per cigarette and the timing of puffs were the same as under the "Restaurant" condition.

Measurements were continued for $1 \mathrm{~h}$. When the test was finished, all smokers left the chamber and the chamber was ventilated for the next IAQ experiment. Five different scenarios were examined for each simulation, as follows: "With person", "IT1.0a with person", "IT2.0a with person", "DT2.2a with person", and "Cigarette with person". "With person" indicates that persons were present, but the heating tobacco systems or conventional cigarettes were not used in the chamber, "IT1.0a, IT2.0a, and DT2.2a with person" indicate that persons used the relevant heating tobacco systems in the chamber, and "Cigarette with person" indicates that persons smoked conventional cigarettes in the chamber. Each scenario in each simulated environment was replicated four times. The test plan for each scenario and the time schedule for each day are shown in Supplementary Table S2. The number of tests per day was four, with appropriate breaks. The test period was 10 days and each scenario, except for "Cigarette with person", was set randomly each day. "Cigarette with person" was performed at the end of each test day because it was expected to produce a much higher concentration of indoor air constituents than the other tests.

\subsection{Chemical analyses for IAQ measurements}

\section{(1) Tobacco-specific nitrosamines (TSNA)}

TSNA ( $N$-nitrosonornicotine, NNN; $N$-nitrosoanatabine, NAT; $N$-nitrosoanabasine, NAB; 4-(N-nitrosomethylamino)1-(3-pyridyl)-1-butanone, NNK) were measured as follows. Air samples were passed through an XAD-7 sorbent tube (SKC Ltd.) at a sampling flow rate of $1 \mathrm{~L} / \mathrm{min}$. TSNA were extracted from XAD-7 with methanol and $100 \mathrm{mM}$ ammonium acetate in water $(40: 60, \mathrm{v} / \mathrm{v})$ containing NNNd4, NAT-d4, NAB-d4, and NNK-d4 (internal standard), and quantified by liquid chromatography-mass spectrometry (LC-MS/MS; LC: 1290 Infinity, Agilent Technologies, Santa Clara, CA, USA; MS/MS: Triple Quad 4500, ABSciex, Framingham, MA, USA). Gradient separation was performed using a BEH C18 column $(2.1 \times 50 \mathrm{~mm}, 1.7 \mu \mathrm{m}$; Waters Corporation, Milford, MA, USA), using $10 \mathrm{mM}$ ammonium acetate in water as mobile phase $A$ and $0.1 \%$ acetic acid in methanol as mobile phase B. Limits of detection (LOD) and quantitation (LOQ) of TSNAs were three times and ten times the standard deviation of the smallest concentration of standards, respectively. This method was newly developed in-house to measure the constituents at low concentration level. The method was validated by our recovery test and breakthrough test in advance of IAQ measurement (Supplementary Tables S18 and S19).

\section{(2) Low molecular weight carbonyls}

Carbonyls (formaldehyde, acetaldehyde, acetone, acrolein, propionaldehyde, crotonaldehyde, methyl ethyl ketone (MEK), and $n$-butyraldehyde) were measured according to ISO 16000-3:2001 [23]. Air samples were passed through a Sep-Pak XPoSure Aldehyde Sampler (Waters Corporation, Milford, MA, USA) at a flow rate of 
$1.0 \mathrm{~mL} / \mathrm{min}$ to collect and derivatize carbonyls. The SepPak is a plastic capsule filled with silica granules coated with 2,4-dinitrophenylhydrazine (DNPH). The eight types of carbonyls derivatized by DNPH were extracted with acetonitrile containing acetone-d6-DNPH ( $>98 \%$ purity, Kanto Chemical Co.; internal standard). The extracted carbonyl solution was quantified by LC-MS/MS (LC: 1290 Infinity, Agilent Technologies, Santa Clara, CA, USA; MS/ MS: Triple Quad 5500, AB Sciex, Framingham, MA, USA). Isocratic separation was performed using an Acclaim C18 column $(150 \times 3.0 \mathrm{~mm}, 3 \mu \mathrm{m}$; Thermo Fisher Scientific Inc., Sunnyvale, CA, USA), with $4 \mathrm{mM}$ ammonium acetate in water and acetonitrile $(45: 55, \mathrm{v} / \mathrm{v})$ as the mobile phase. The LOD and LOQ of carbonyls were three times and ten times the standard deviation of the smallest concentration of standards, respectively.

(3) Volatile organic compounds (VOC) and total volatile organic compounds (TVOC)

VOC and TVOC were determined according to ISO 160006:2011 [24] and ISO 16017-1:2000 [25]. Air samples of VOC were fed into an Air Toxics ATD tube (Markes International Ltd., Llantrisant, UK) at an air sampling flow rate of $50 \mathrm{~mL} / \mathrm{min}$. Air samples of TVOC were fed into a Material emission ATD tube (Markes International Ltd., Llantrisant, UK) at an air sampling flow rate of $100 \mathrm{~mL} /$ min. Constituents of VOC and TVOC were measured by gas chromatography-mass spectrometry (GC-MS; Instrumentation: 7890B, 5977B, and VF-1, Agilent Technologies, Santa Clara, CA, USA) coupled to a thermal desorption system (TD100-xr, Markes International Ltd., Llantrisant, UK). The LOD and LOQ of VOC and TVOC were three times and ten times the standard deviation of the smallest concentration of standards, respectively.

(4) Polycyclic aromatic hydrocarbon (PAH) benzo[a]pyrene $(\mathrm{BaP})$

BaP was measured as follows. Air samples were passed through a 44-mm glass fiber filter (Borgwaldt KC, Hamburg, Germany) at an air sampling flow rate of $2 \mathrm{~L} / \mathrm{min}$. The pads were extracted with cyclohexane $(20 \mathrm{~mL})$ and the cyclohexane extracts were filtered through filter paper. A portion of the filtered extract was cleaned up by solid phase extraction (SPE) using an EX-MULTI system (Shoko Science Inc., Yokohama, Japan) and analyzed by high-performance liquid chromatography (HPLC; 1290 Infinity, Agilent Technologies, Santa Clara, CA, USA) with fluorescence detection for quantification. Gradient separation was performed on an X-Bridge $\mathrm{C} 18 \mathrm{col}$ umn $(4.6 \times 150 \mathrm{~mm}, 3.5 \mu \mathrm{m}$; Waters Corporation, Milford, MA, USA) using acetonitrile as mobile phase $A$ and pure water as mobile phase $\mathrm{B}$. The $\mathrm{LOD}$ and $\mathrm{LOQ}$ of $\mathrm{BaP}$ were three times and ten times the standard deviation of the smallest concentration of standards, respectively.

\section{(5) Aromatic amines (PAA)}

PAA (1-aminonaphthalene, 2-aminonaphthalene, 3-aminobiphenyl, and 4-aminobiphenyl) were measured as follows. Air samples were passed through a 44-mm glass fiber filter (Borgwaldt KC, Hamburg, Germany) at an air sampling flow rate of $2 \mathrm{~L} / \mathrm{min}$. The pads were extracted with $5 \%$ hydrochloric acid solution containing d7-1-aminonaphthalene (internal standard). A filtered extract was cleaned up and derivatized with pentafluoropropionic acid anhydride (PFPA) and passed through a florisil column by SPE using a Rapid Trace system (PerkinElmer Inc., Massachusetts, USA). The sample was quantified using GC/MS (7890A, 5975C, and HP-5MS, Agilent Technologies, Santa Clara, CA, USA). The LOD and LOQ of PAA were three times and ten times the standard deviation of the smallest concentration of standards, respectively.

\section{(6) Mercury}

Mercury was measured as follows. Air samples were passed thorough two impingers placed in series containing 20 and $10 \mathrm{~mL}$ of acidified potassium permanganate solution, respectively. The impinger solutions were mixed with hydrogen peroxide and then subjected to microwave digestion. Excess potassium permanganate was reduced with hydroxylamine hydrochloride and made up to a final volume of $100 \mathrm{~mL}$. The digestate was then analyzed by cold vapor atomic absorption spectroscopy at $253.7 \mathrm{~nm}$ using a continuous flow vapor generator to reduce divalent mercury to its atomic state with stannous chloride. The LOD and LOQ of mercury were three times and ten times the standard deviation of the smallest concentration of standards, respectively.

\section{(7) Trace metals}

Metals (lead, cadmium, chromium, nickel, beryllium, and arsenic) were measured as follows. Air samples were passed through a quartz filter pad (QM-A quartz filter, Whatman) at an air sampling flow rate of $1 \mathrm{~L} / \mathrm{min}$. The pad was extracted with $5 \%(\mathrm{v} / \mathrm{v})$ nitric acid in water $(10 \mathrm{~mL})$. The solution was gently shaken using a shaker for $30 \mathrm{~min}$ at $180 \mathrm{rpm}$. The sample was subjected to inductively coupled argon plasma mass spectrometry (ICP-MS; ICP-MS 7900, Agilent Technologies, Santa Clara, CA, USA) and quantified. The LOD and LOQ of metals were three times and ten times the standard deviation of the smallest concentration of standards, respectively. This method was 
newly developed in-house to measure the constituents at low concentration level. The method was validated by our recovery test and breakthrough test in advance of IAQ measurement (Supplementary Tables S20 and S21).

(8) Environmental tobacco smoke vapor phase markers (ETS-V)

Nicotine and 3-ethenylpyridine (3-EP) were measured according to ISO 18145:2003 [26]. Air samples were passed through XAD-4 (SUPELCO, Bellefonte, PA, USA, and SigmaAldrich Co. LLC., St. Louis, MO, USA) at a flow rate of $1 \mathrm{~L} /$ min to adsorb both constituents. Nicotine and 3-EP were extracted from XAD-4 with ethyl acetate containing quinoline (internal standard), and quantified by GC-MS (Instrumentation: 7890A, 5975C, and DB-WAX, Agilent Technologies, Santa Clara, CA, USA). The LOD and LOQ of ETS-V were three times and ten times the standard deviation of the smallest concentration of standards, respectively.

(9) Environmental tobacco smoke particulate phase markers (ETS-P)

Respirable suspended particles (RSP) mass (using gravimetric measurement), ultraviolet particulate matter (UVPM), and fluorescent particulate matter (FPM) were determined according to ISO 15593:2001 [27]. Solanesol was determined according to ISO 18144:2003 [28]. Air samples were passed through a polytetrafluoroethylene (PTFE) membrane filter (Millex-LH, Merck Millipore Inc., Massachusetts, USA), without using an impactor or cyclone. Consequently, RSP, UVPM, FPM, and solanesol included nonrespirable particles larger than $4 \mu \mathrm{m}$ in aerodynamic diameter to overestimate the mass. The air sampling flow rate was $2 \mathrm{~L} / \mathrm{min}$. First, RSP was measured using the PTFE filter with a balance (XPR2U, Mettler-Toledo International Inc., Columbus, $\mathrm{OH}, \mathrm{USA}$ ), then UVPM, FPM, and solanesol were extracted from this filter with methanol and quantified by HPLC (1260 Infinity, Agilent Technologies, Santa Clara, CA, USA) with ultraviolet and fluorescence detection. For UVPM and FPM, no HPLC column was used. For solanesol, an isocratic separation was performed using an X-Bridge C18 column $(4.6 \times 150$ mm, $3.5 \mu \mathrm{m}$; Waters Corporation, Milford, MA, USA), with methanol as the mobile phase. The LOD and LOQ of RSP were three times and ten times the standard deviation of the mean weight of blank filter, respectively, as calculated from five replicates. The LOD and LOQ of UVPM, FPM, and solanesol were three times and ten times the standard deviation of the smallest concentration of standards, respectively.

(10) Propylene glycol (PG) and glycerol (G)
Propylene glycol and glycerol were measured as follows. Air samples were passed through an XAD-7 sorbent tube (SKC Ltd.) at a sampling flow rate of $1 \mathrm{~L} / \mathrm{min}$. Propylene glycol and glycerol were collected on the XAD-7 tube, extracted with $\mathrm{N}, \mathrm{N}$-dimethylformamide (DMF) containing 1,3-butanediol as an internal standard, and then silylated with $\mathrm{N}, \mathrm{O}$-bis(trimethylsilyl)trifluoroacetamide (BSTFA). Concentrations were determined by GC-MS (Instrumentation: 7890A, 5975C, and DB-5, Agilent Technologies, Santa Clara, CA, USA). The LOD and LOQ of propylene glycol and glycerol were three times and ten times the standard deviation of the smallest concentration of standards, respectively.

\section{(11) Carbon monoxide (CO)}

CO was measured using a carbon monoxide meter (APMA-370, HORIBA Inc., Kyoto, Japan) with an air sampling flow rate of $1.5 \mathrm{~L} / \mathrm{min}$ and data sampling cycle of $1 \mathrm{~min}$. To determine the $\mathrm{CO}$ concentration, the signal responses of electrolysis and nondispersive infrared (NDIR) sensors were quantified. APMA-370 was connected to a sampling point with Tygon ${ }^{\circledR}$ tubing (SaintGobain Performance Plastices, Akron, $\mathrm{OH}, \mathrm{USA}$ ). The lowest measurable concentration of this system was $0.05 \mathrm{ppm}$ (ppm, parts per million volume basis).

\section{(12) Carbon dioxide $\left(\mathrm{CO}_{2}\right)$}

$\mathrm{CO}_{2}$ was measured with a $\mathrm{COX}-3$ carbon monoxide/dioxide meter (Sibata Scientific Technology Ltd., Saitama, Japan) with an air sampling flow rate of $0.4 \pm 0.1 \mathrm{~L} / \mathrm{min}$ and data sampling cycle of $1 \mathrm{~min}$. To determine the $\mathrm{CO}_{2}$ concentration, the signal responses of electrolysis and NDIR sensors were quantified. The COX-3 m was connected to a sampling point with Tygon ${ }^{\circledR}$ tubing (SaintGobain Performance Plastices, Akron, $\mathrm{OH}$, USA). The lowest measurable concentration of this system was $10 \mathrm{ppm}$.

\section{(13) Suspended particulate matter (SPM)}

SPM was measured using a piezobalance dust monitor (Model 3521, Kanomax Japan Inc., Osaka, Japan) and light scattering dust indicator (LD-3K2, Sibata Scientific Technology Ltd., Saitama, Japan). The aerosol sampling flow rate was $1 \mathrm{~L} / \mathrm{min}$ with a data sampling cycle of $1 \mathrm{~min}$ (piezobalance), and $3.4 \mathrm{~L} / \mathrm{min}$ with a data sampling cycle of $1 \mathrm{~min}$ (light scattering). For this measurement only, supply air was sampled at $\mathrm{SP}_{\text {supply, }}$ as shown in Fig. 2. Each inlet port of monitor 3521 was connected to each sampling point with Tygon ${ }^{\circledast}$ tubing (Saint-Gobain Performance Plastices, Akron, OH, USA, $4.76 \mathrm{~mm}$ I.D. $\times 15 \mathrm{~cm}$ ). The lowest 
measurable concentrations of the piezobalance and light scattering instruments were $0.01 \mathrm{mg} / \mathrm{m}^{3}$ and $0.52 \mu \mathrm{g} / \mathrm{m}^{3}$, respectively.

\section{(14) Ammonia $\left(\mathrm{NH}_{3}\right)$ and nitrogen oxides $\left(\mathrm{NO}_{x}\right)$}

Ammonia $\left(\mathrm{NH}_{3}\right)$ and nitrogen oxides $\left(\mathrm{NO}_{x}\right.$; nitrogen oxide (NO) and nitrogen dioxide $\left(\mathrm{NO}_{2}\right)$ ) were measured using an ammonia analyzer (Model 17i, Thermo Fisher Scientific Inc., Sunnyvale, CA, USA) with an air sampling flow rate of $0.6 \mathrm{~L} / \mathrm{min}$ and data sampling cycle of $10 \mathrm{~s}$. To determine the $\mathrm{NH}_{3}$ concentrations, chemiluminescence technology for a reaction producing characteristic luminescence with an intensity proportional to the amount of NO was used in this system. The lowest measurable concentration of this system was $1 \mathrm{ppb}$ (ppb, parts per billion volume basis).

\subsection{Data treatment in this study}

Each scenario in each simulated environment was replicated four times. These four data sets were treated as follows. (1) If three or more out of four of the measured data sets were higher than the LOQ, the arithmetic mean and its $95 \%$ confidence interval $(95 \% \mathrm{Cl})$ were given; (2) when the measured value was below the LOQ by two points or more, the median value was calculated, but not the standard error; (3) the median value was the average of the two middle values out of four data sets, and when two or more data sets included values below the $L O D$ and $L O Q$, the equations $\mathrm{LOQ}=(\mathrm{LOQ}+\mathrm{LOD}) / 2$ and $\mathrm{LOD}=\mathrm{LOD} / 2$ were used; and (4) if the calculated median value was below the LOD or LOQ, $<$ LOD or $<$ LOQ were used, respectively.

The main objective of the analysis was to compare the indoor air concentrations of the measured constituents for $C_{\text {exhaust }}$ ("each product with person") and $C_{\text {exhaust }}$ ("With person") in the simulated environment. The calculated data were evaluated whether the indoor air concentrations increased or not as follows. (1) If both $C_{\text {exhaust }}$ ("each product with person") and $C_{\text {exhaust }}$ ("With person") were given as the arithmetic mean and its $95 \% \mathrm{Cl}$, the data were statistically tested using an $f$-test for equality of variance and a $t$-test for significant difference $(p<0.05$ and two-sided test); (2) if one or both were not given as the arithmetic mean and its $95 \% \mathrm{Cl}$, they were evaluated as an increase in the case of a numerical rise (e.g., $<\mathrm{LOD}<\rightarrow \mathrm{LOQ}$ or $<\mathrm{LOD} /<\mathrm{LOQ} \rightarrow$ median or arithmetic mean).

The factors that increased the indoor air concentrations were evaluated based on the following three statuses. (Status1) "Actual indoor air concentration increase ("> with person")": when the indoor concentration of the constituent increased and the constituents could be detected, above the limit of detection value, from the data of the constituent in the mainstream emission. If the constituents were not measured in the mainstream emission, they were evaluated by simply using the comparison of the indoor air concentrations; (Status2) "Not actual indoor air concentration increase" when using the heating tobacco systems: when the indoor concentration of the constituent increased, but the constituents could not be detected, below the limit of detection (BDL), from the data of the constituent in the mainstream emission; (Status3) "Not substantial increase": when the indoor concentration of the constituent did not increase regardless of whether the constituents were measured in mainstream emissions. For other cases, details are given in the Sect. 3.

\section{Results}

\section{1 "Restaurant" conditions}

The results of indoor air analysis under "Restaurant" conditions are shown in Table 2 and Supplementary Table S7. A comparison of indoor air concentrations was performed

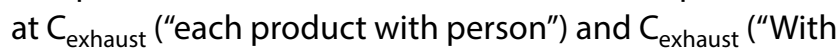
person") (Supplementary Tables S9-S12). The $C_{\text {exhaust }}$ and $C_{B G}$ values corresponded to concentrations measured at $\mathrm{SP}_{\text {exhaust }}$ inside the chamber and $\mathrm{SP}_{\text {outside }}$ or $\mathrm{SP}_{\text {supply' }}$ respectively (Fig. 2).

The $C_{\text {exhaust }}$ value of TVOC and glycerol when using IT1.0a ("IT1.0a with person") was higher than that in the presence of people only ("With person"; $p=0.0456$ and 0.0224) (Supplementary Tables S9). Statistical analysis could not be performed by comparing "IT1.0a with person" and "With person" using the $C_{\text {exhaust }}$ values of 1,3-butadiene, acrylonitrile, benzene, and pyridine. However, the

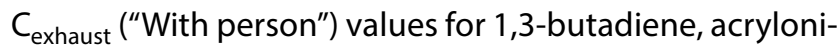
trile, and benzene were $<$ LOD, while their $C_{\text {exhaust }}$ ("IT1.0a with person") values were detected $(<L O Q)$. The $C_{\text {exhaust }}$ ("With person") value for pyridine was $<L O Q$, while the $C_{\text {exhaust }}$ ("IT1.0a with person") value was quantified (95\% $\mathrm{Cl}$ given). As these constituents (1,3-butadiene, acrylonitrile, benzene, and pyridine) were not detected by mainstream emission analysis (Supplementary Table S3 and S9), their results were not attributed to actual concentration increases, but factors other than product use. All other constituents showed no actual increase in indoor air concentration. As a result, substantial concentration increases due to product use were observed for two constituents, TVOC and glycerol (Table 2 and Supplementary Table S9).

The $C_{\text {exhaust }}$ values of propionaldehyde, TVOC, and glycerol for IT2.0a ("IT2.0a with person") were higher than those in the presence of people only ("With person"; $p=0.00776,0.0310$, and 0.0314) (Supplementary Tables S10). As propionaldehyde was not detected by mainstream emission analysis (Supplementary Tables S4 and 
Table 2 Summary of indoor air concentration $\left(C_{\text {exhaust }}\right)$ under simulated "Restaurant" conditions

\begin{tabular}{|c|c|c|c|c|c|c|}
\hline \multirow[t]{2}{*}{ Constituent } & \multirow[t]{2}{*}{ Unit } & With person & & IT2.0a with person & DT2.2a with person & Cigarette with person \\
\hline & & \multicolumn{5}{|c|}{ Mean indoor air concertation $\mathrm{C}_{\text {exhaust }} \pm 95 \% \mathrm{Cl}$ (Median) } \\
\hline \multicolumn{7}{|l|}{ TSNA } \\
\hline NNN & $\left(\mathrm{ng} / \mathrm{m}^{3}\right)$ & $<\mathrm{LOD}$ & $<$ LOD & $<$ LOD & $(2.85)^{* *}$ & $3.43 \pm 0.32^{* *}$ \\
\hline NAT & $\left(\mathrm{ng} / \mathrm{m}^{3}\right)$ & $<$ LOD & $<$ LOD & $<$ LOD & $<\mathrm{LOQ}^{* *}$ & $2.70 \pm 0.37^{* *}$ \\
\hline NAB & $\left(\mathrm{ng} / \mathrm{m}^{3}\right)$ & $<$ LOD & $<$ LOD & $<$ LOD & $<$ LOD & $0.987 \pm 0.057^{* *}$ \\
\hline NNK & $\left(\mathrm{ng} / \mathrm{m}^{3}\right)$ & $<$ LOD & $<$ LOD & $<$ LOD & $<\mathrm{LOQ}^{* *}$ & $23.3 \pm 4.2^{* *}$ \\
\hline \multicolumn{7}{|l|}{ Carbonyl } \\
\hline Formaldehyde & $\left(\mu \mathrm{g} / \mathrm{m}^{3}\right)$ & $5.26 \pm 1.01$ & $5.44 \pm 1.17$ & $5.54 \pm 0.72$ & $6.45 \pm 0.48$ & $93.9 \pm 11.4^{* *}$ \\
\hline Acetaldehyde & $\left(\mu \mathrm{g} / \mathrm{m}^{3}\right)$ & $4.62 \pm 0.26$ & $4.52 \pm 0.21$ & $5.42 \pm 0.32$ & $10.4 \pm 1.1^{* *}$ & $76.9 \pm 15.9^{* *}$ \\
\hline Acetone & $\left(\mu \mathrm{g} / \mathrm{m}^{3}\right)$ & $35.3 \pm 2.1$ & $36.4 \pm 0.5$ & $42.5 \pm 2.9$ & $55.6 \pm 8.8$ & $479 \pm 70^{* *}$ \\
\hline Acrolein & $\left(\mu \mathrm{g} / \mathrm{m}^{3}\right)$ & $0.0717 \pm 0.020$ & $0.0845 \pm 0.0214$ & $0.0640 \pm 0.0083$ & $0.100 \pm 0.006$ & $1.360 \pm 0.448$ \\
\hline Propionaldehyde & $\left(\mu \mathrm{g} / \mathrm{m}^{3}\right)$ & $0.618 \pm 0.040$ & $0.734 \pm 0.059$ & $0.803 \pm 0.026^{*}$ & $1.17 \pm 0.07^{* *}$ & $11.0 \pm 2.0^{* *}$ \\
\hline Crotonaldehyde & $\left(\mu \mathrm{g} / \mathrm{m}^{3}\right)$ & $0.0432 \pm 0.0068$ & $0.0442 \pm 0.0066$ & $0.0429 \pm 0.0040$ & $0.0705 \pm 0.0057^{*}$ & $0.598 \pm 0.088^{* *}$ \\
\hline MEK & $\left(\mu \mathrm{g} / \mathrm{m}^{3}\right)$ & $2.63 \pm 0.31$ & $2.90 \pm 0.43$ & $2.53 \pm 0.08$ & $3.94 \pm 0.40^{*}$ & $41.6 \pm 10.0^{* *}$ \\
\hline n-Butyraldehyde & $\left(\mu \mathrm{g} / \mathrm{m}^{3}\right)$ & $0.900 \pm 0.087$ & $0.929 \pm 0.075$ & $1.13 \pm 0.12$ & $2.08 \pm 0.30^{* *}$ & $10.8 \pm 0.9^{* *}$ \\
\hline \multicolumn{7}{|l|}{ VOC } \\
\hline 1,3-Butadiene & $\left(\mu \mathrm{g} / \mathrm{m}^{3}\right)$ & $<$ LOD & $<\mathrm{LOQ}^{*}$ & $<\mathrm{LOQ}^{*}$ & $<\mathrm{LOQ}^{*}$ & $71.9 \pm 10.2^{* *}$ \\
\hline Isoprene & $\left(\mu \mathrm{g} / \mathrm{m}^{3}\right)$ & $3.64 \pm 0.73$ & $3.60 \pm 0.46$ & $3.89 \pm 0.40$ & $4.15 \pm 0.45$ & $147 \pm 5^{* *}$ \\
\hline Acrylonitrile & $\left(\mu \mathrm{g} / \mathrm{m}^{3}\right)$ & $<$ LOD & $<\mathrm{LOQ}^{*}$ & $<\mathrm{LOQ}^{*}$ & $<\mathrm{LOQ}^{*}$ & $5.33 \pm 0.18^{* *}$ \\
\hline Benzene & $\left(\mu \mathrm{g} / \mathrm{m}^{3}\right)$ & $<$ LOD & $<\mathrm{LOQ}^{*}$ & $<\mathrm{LOQ}^{*}$ & $<\mathrm{LOQ}^{* *}$ & $14.1 \pm 0.7^{* *}$ \\
\hline Toluene & $\left(\mu \mathrm{g} / \mathrm{m}^{3}\right)$ & $3.23 \pm 0.69$ & $3.80 \pm 0.94$ & $2.21 \pm 0.21$ & $3.11 \pm 0.56$ & $25.4 \pm 1.3^{* *}$ \\
\hline Pyridine & $\left(\mu \mathrm{g} / \mathrm{m}^{3}\right)$ & $<$ LOQ & $1.37 \pm 0.09^{*}$ & $1.36 \pm 0.19^{*}$ & $1.59 \pm 0.14^{* *}$ & $9.51 \pm 0.53^{* *}$ \\
\hline Styrene & $\left(\mu \mathrm{g} / \mathrm{m}^{3}\right)$ & $<\mathrm{LOQ}$ & $<\mathrm{LOQ}$ & $<\mathrm{LOQ}$ & $<\mathrm{LOQ}$ & $4.98 \pm 0.27^{* *}$ \\
\hline \multicolumn{7}{|l|}{ TVOC } \\
\hline TVOC & $\left(\mu \mathrm{g} / \mathrm{m}^{3}\right)$ & $42.1 \pm 13.2$ & $83.2 \pm 9.2^{* *}$ & $84.2 \pm 7.5^{* *}$ & $104 \pm 23$ & $538 \pm 95^{* *}$ \\
\hline \multicolumn{7}{|l|}{ PAH } \\
\hline Benz [a] pyrene & $\left(\mathrm{ng} / \mathrm{m}^{3}\right)$ & $<$ LOD & $<$ LOD & $<$ LOD & $<$ LOD & $<\mathrm{LOQ}^{* *}$ \\
\hline \multicolumn{7}{|l|}{$P A A$} \\
\hline 1-Aminonaphthalene & $\left(\mathrm{ng} / \mathrm{m}^{3}\right)$ & $<$ LOD & $<$ LOD & $<\mathrm{LOQ}^{*}$ & $<$ LOD & $9.85 \pm 0.62^{* *}$ \\
\hline 2-Aminonaphthalene & $\left(\mathrm{ng} / \mathrm{m}^{3}\right)$ & $<$ LOD & $<$ LOD & $<$ LOD & $<$ LOD & $17.7 \pm 1.3^{* *}$ \\
\hline 3-Aminobiphenyl & $\left(\mathrm{ng} / \mathrm{m}^{3}\right)$ & $<$ LOD & $<$ LOD & $<$ LOD & $<$ LOD & $5.35 \pm 0.33^{* *}$ \\
\hline 4-Aminobiphenyl & $\left(\mathrm{ng} / \mathrm{m}^{3}\right)$ & $<$ LOD & $<$ LOD & $<$ LOD & $<$ LOD & $4.13 \pm 0.20^{* *}$ \\
\hline \multicolumn{7}{|l|}{ Mercury } \\
\hline $\mathrm{Hg}$ & $\left(\mathrm{ng} / \mathrm{m}^{3}\right)$ & $<\mathrm{LOQ}$ & $<\mathrm{LOQ}$ & $<\mathrm{LOQ}$ & $<\mathrm{LOQ}$ & $<\mathrm{LOQ}$ \\
\hline \multicolumn{7}{|l|}{ Metal } \\
\hline Lead $(\mathrm{Pb})$ & $\left(\mathrm{ng} / \mathrm{m}^{3}\right)$ & $<$ LOD & $<$ LOD & $<$ LOD & $<$ LOD & $<\mathbf{L O Q}^{* *}$ \\
\hline Cadmium (Cd) & $\left(\mathrm{ng} / \mathrm{m}^{3}\right)$ & $<$ LOD & $<$ LOD & $<$ LOD & $<$ LOD & $<\mathbf{L O Q}^{* *}$ \\
\hline Chromium (Cr) & $\left(\mathrm{ng} / \mathrm{m}^{3}\right)$ & $<$ LOD & $<$ LOD & $<$ LOD & $<$ LOD & $<$ LOD \\
\hline Nickel (Ni) & $\left(\mathrm{ng} / \mathrm{m}^{3}\right)$ & $<$ LOD & $<$ LOD & $<$ LOD & $<$ LOD & $<$ LOD \\
\hline Beryllium (Be) & $\left(\mathrm{ng} / \mathrm{m}^{3}\right)$ & $<$ LOD & $<$ LOD & $<$ LOD & $<$ LOD & $<$ LOD \\
\hline Arsenic (As) & $\left(\mathrm{ng} / \mathrm{m}^{3}\right)$ & $<$ LOD & $<$ LOD & $<$ LOD & $<$ LOD & $<$ LOD \\
\hline \multicolumn{7}{|l|}{$E T S-V$} \\
\hline Nicotine & $\left(\mu \mathrm{g} / \mathrm{m}^{3}\right)$ & $0.75 \pm 0.24$ & $0.77 \pm 0.25$ & $1.19 \pm 0.32$ & $5.60 \pm 2.24$ & $101 \pm 5^{* *}$ \\
\hline 3-ethenylprydine & $\left(\mu \mathrm{g} / \mathrm{m}^{3}\right)$ & $<$ LOQ & $<$ LOQ & $<$ LOQ & $<$ LOQ & $17.6 \pm 1.2^{* *}$ \\
\hline \multicolumn{7}{|l|}{$E T S-P$} \\
\hline RSP & $\left(\mathrm{mg} / \mathrm{m}^{3}\right)$ & $<\mathrm{LOQ}$ & $<\mathrm{LOQ}$ & $(0.344)^{*}$ & $(0.221)^{*}$ & $0.536 \pm 0.042^{* *}$ \\
\hline UVPM (THBP) & $\left(\mu \mathrm{g} / \mathrm{m}^{3}\right)$ & $<\mathrm{LOQ}$ & $<\mathrm{LOQ}$ & $<\mathrm{LOQ}$ & $<\mathrm{LOQ}$ & $62.9 \pm 8.0^{* *}$ \\
\hline FPM (Scopoletin) & $\left(\mu \mathrm{g} / \mathrm{m}^{3}\right)$ & $<\mathrm{LOQ}$ & $<\mathrm{LOQ}$ & $<\mathrm{LOQ}$ & $0.0533 \pm 0.0042^{*}$ & $17.2 \pm 1.5^{* *}$ \\
\hline Solanesol & $\left(\mu \mathrm{g} / \mathrm{m}^{3}\right)$ & $<$ LOD & $<$ LOD & $<$ LOD & $<$ LOD & $14.7 \pm 2.6^{* *}$ \\
\hline
\end{tabular}


Table 2 (continued)

\begin{tabular}{|c|c|c|c|c|c|c|}
\hline \multirow[t]{2}{*}{ Constituent } & \multirow[t]{2}{*}{ Unit } & With person & IT1.0a with person & IT2.0a with person & DT2.2a with person & Cigarette with person \\
\hline & & \multicolumn{5}{|c|}{ Mean indoor air concertation $C_{\text {exhaust }} \pm 95 \% \mathrm{Cl}$ (Median) } \\
\hline \multicolumn{7}{|l|}{$P G / G$} \\
\hline Propylene glycol & $\left(\mu \mathrm{g} / \mathrm{m}^{3}\right)$ & $11.2 \pm 3.0$ & $94.8 \pm 32.4$ & $106 \pm 34$ & $29.9 \pm 7.7$ & $32.8 \pm 3.2^{* *}$ \\
\hline Glycerol & $\left(\mu \mathrm{g} / \mathrm{m}^{3}\right)$ & $13.4 \pm 2.3$ & $54.2 \pm 10.4^{* *}$ & $90.9 \pm 20.5^{* *}$ & $37.3 \pm 6.9^{* *}$ & $24.8 \pm 4.5$ \\
\hline \multicolumn{7}{|l|}{$\mathrm{CO} / \mathrm{CO}_{2}$} \\
\hline $\mathrm{CO}$ & (ppm) & $0.302 \pm 0.041$ & $0.330 \pm 0.025$ & $0.272 \pm 0.014$ & $0.298 \pm 0.028$ & $2.36 \pm 0.10^{* *}$ \\
\hline $\mathrm{CO}_{2}$ & (ppm) & $790 \pm 26$ & $800 \pm 44$ & $790 \pm 30$ & $800 \pm 27$ & $790 \pm 27$ \\
\hline \multicolumn{7}{|l|}{ SPM } \\
\hline Piezobalance & $\left(\mathrm{mg} / \mathrm{m}^{3}\right)$ & $<$ LOD & $<$ LOD & $<$ LOD & $<$ LOD & $0.354 \pm 0.033^{* *}$ \\
\hline Light scattering & $\left(\mu \mathrm{g} / \mathrm{m}^{3}\right)$ & $0.700 \pm 0.183$ & $2.22 \pm 1.10$ & $7.67 \pm 3.26$ & $7.08 \pm 2.11$ & $283 \pm 63^{* *}$ \\
\hline \multicolumn{7}{|l|}{ Ammonia } \\
\hline $\mathrm{NH}_{3}$ & (ppb) & $42.2 \pm 6.1$ & $47.1 \pm 4.9$ & $44.7 \pm 3.84$ & $46.2 \pm 5.4$ & $357 \pm 21^{* *}$ \\
\hline \multicolumn{7}{|l|}{$N O_{X}$} \\
\hline NO & (ppb) & $5.62 \pm 2.23$ & $3.24 \pm 0.52$ & $2.44 \pm 0.36$ & $2.08 \pm 0.27$ & $33.7 \pm 5.8^{* *}$ \\
\hline $\mathrm{NO}_{2}$ & (ppb) & $11.3 \pm 2.1$ & $12.5 \pm 2.5$ & $8.43 \pm 0.66$ & $11.3 \pm 1.7$ & $16.4 \pm 2.0$ \\
\hline $\mathrm{NO}+\mathrm{NO}_{2}$ & (ppb) & $16.9 \pm 3.4$ & $15.7 \pm 2.6$ & $10.9 \pm 0.7$ & $13.3 \pm 1.8$ & $49.7 \pm 7.4^{* *}$ \\
\hline
\end{tabular}

The constituents evaluated as "Status1" displayed in bold

**Status1, "Actual indoor air concentration increase (" > With person")", shown in "Data treatment in this study"

*Status2, "Not actual indoor air concentration increase", shown in "Data treatment in this study"

S10), this change was not attributed to an actual concentration increase, but factors other than product use. Statistical analysis could not be performed by comparing "IT2.0a with person" and "With person" using the $C_{\text {exhaust }}$ values of 1,3-butadiene, acrylonitrile, benzene, pyridine, 1-aminonaphthalene, and RSP. However, the $C_{\text {exhaust }}$ ("With person") values of 1,3-butadiene, acrylonitrile, benzene, and 1-aminonaphthalene were $<$ LOD, while their $C_{\text {exhaust }}$ ("IT2.0a with person") values were detected ( $<L O Q)$. The $C_{\text {exhaust }}$ ("With person") values of pyridine and RSP were $<\mathrm{LOQ}$, while their $C_{\text {exhaust }}$ ("IT2.0a with person") values were quantified ( $95 \% \mathrm{Cl}$ given or median). As 1,3-butadiene, acrylonitrile, benzene, pyridine, and 1-aminonaphthalene were not detected by mainstream emission analysis (Supplementary Tables S4 and S10), their results were not attributed to actual concentration increases, but factors other than product use. As RSP showed a higher value $\left(0.344 \mathrm{mg} / \mathrm{m}^{3}\right)$ compared with quantitative values from other dust analyzers (piezo, $<0.01 \mathrm{mg} / \mathrm{m}^{3}$; light scattering, $7.67 \pm 3.26 \mu \mathrm{g} /$ $\left.\mathrm{m}^{3}\right)$, it was considered necessary to re-examine the analytical system. All other constituents resulted in no actual increase in indoor air concentration. As a result, substantial concentration increases due to product use were observed for two constituents, TVOC and glycerol (Table 2 and Supplementary Table S10).

The $C_{\text {exhaust }}$ values of acetaldehyde, propionaldehyde, crotonaldehyde, MEK, $n$-butyraldehyde, and glycerol when using DT2.2a ("DT2.2a with person") increased compared with those in the presence of people only ("With person"; $p=0.00988,0.000382,0.0219,0.0403,0.00910$, and 0.0362) (Supplementary Tables S11). As crotonaldehyde and MEK were not detected by mainstream emission analysis (Supplementary Tables S5 and S11), their results were not attributed to actual concentration increases, but factors other than product use. Statistical analysis could not be performed by comparing "DT2.2a with person" and "With person" using the $C_{\text {exhaust }}$ values of NNN, NAT, NNK, 1,3-butadiene, acrylonitrile, benzene, pyridine, RSP, and FPM (expressed as scopoletin equivalents). However, the

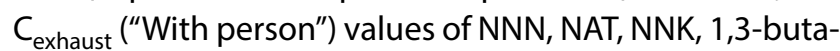
diene, acrylonitrile, and benzene were $\angle L O D$, while their $C_{\text {exhaust }}$ ("DT2.2a with person") were detected (<LOQ or median). The $C_{\text {exhaust }}$ ("With person") values of pyridine, $\mathrm{RSP}$, and FPM were $<\mathrm{LOQ}$, while their $\mathrm{C}_{\text {exhaust }}$ ("DT2.2a with person") values were quantified ( $95 \% \mathrm{Cl}$ given or median). As NNN, NAT, NNK, benzene, and pyridine were detected by mainstream emission analysis (Supplementary Tables S5 and S11), these increased concentrations were attributed to product use. In contrast, as 1,3-butadiene, and acrylonitrile were not detected by mainstream emission analysis (Supplementary Tables S5 and S11), their results were not considered to be caused by actual concentration increases, but factors other than product use. As RSP had a high value $\left(0.221 \mathrm{mg} / \mathrm{m}^{3}\right)$ compared with the quantitative values of other dust analyzers (piezo, $<0.01 \mathrm{mg} / \mathrm{m}^{3}$; light scattering, $7.08 \pm 2.11 \mu \mathrm{g} / \mathrm{m}^{3}$ ), it was considered necessary to reexamine the analytical system. The $C_{\text {exhaust }}$ value of FPM $\left(0.0533 \pm 0.0042 \mu \mathrm{g} / \mathrm{m}^{3}\right)$ was considered to be derived 
from the air supply, because the $C_{B G}$ value of FPM was simi$\operatorname{lar}\left(0.0568 \pm 0.00543 \mu \mathrm{g} / \mathrm{m}^{3}\right.$ ) (Supplementary Table S7). All other constituents resulted in no actual increase in the indoor air concentration. As a result, substantial concentration increases due to product use were observed for nine constituents (NNN, NAT, NNK, acetaldehyde, propionaldehyde, $n$-butyraldehyde, benzene, pyridine, and glycerol; Table 2 and Supplementary Table S11).

Comparing the $\mathrm{C}_{\text {exhaust }}$ values of "Cigarette with person" and "With person" conditions, the increased concentrations of constituents except acrolein, mercury, chromium, nickel, beryllium, arsenic, glycerol, $\mathrm{CO}_{2}$, and $\mathrm{NO}_{2}$ were attributed to product use. Acrolein showed no significant difference by statistical analysis, but the generated concentration was high. As the error bar was considered to be large, it was necessary to review the measurement system. As a result, substantial concentration increases due to cigarette smoke were observed for 39 constituents (Table 2 and Supplementary Table S12).

\section{2 "Residential" conditions}

The results of indoor air analysis under "Residential" conditions are shown in Table 3 and Supplementary Table S8. The measured data were statistically tested and effects on IAQ were evaluated (Supplementary Tables S13-S16). The $C_{\text {exhaust }}$ and $C_{B G}$ values corresponded to concentrations measured at $\mathrm{SP}_{\text {exhaust }}$ inside the chamber and $\mathrm{SP}_{\text {outside }}$ or $\mathrm{SP}_{\text {supply, }}$ respectively (Fig. 2).

Statistical analysis could not be performed by comparing "IT1.0a with person" and "With person" using the $C_{\text {exhaust }}$ values of RSP, FPM, and propylene glycol. However, the $C_{\text {exhaust }}$ ("With person") values of these constituents were $<L O Q$, while their $C_{\text {exhaust }}$ ("IT1.0a with person") values were quantified ( $95 \% \mathrm{Cl}$ given). As RSP had a high value $\left(0.383 \pm 0.064 \mathrm{mg} / \mathrm{m}^{3}\right)$ compared with the quantitative values of other dust analyzers (piezo, $<0.01 \mathrm{mg} /$ $\mathrm{m}^{3}$; light scattering, $1.17 \pm 0.40 \mu \mathrm{g} / \mathrm{m}^{3}$ ), it was considered necessary to reexamine the analytical system. The $C_{\text {exhaust }}$ value of FPM $\left(0.0508 \pm 0.0034 \mu \mathrm{g} / \mathrm{m}^{3}\right)$ was considered to be derived from the air supply because the $C_{B G}$ value of FPM $\left(0.0512 \pm 0.0013 \mu \mathrm{g} / \mathrm{m}^{3}\right)$ was similar. All other constituents showed no actual increase in indoor air concentration. As a result, a substantial concentration increase due to product use was observed for one constituent, namely, propylene glycol (Table 3 and Supplementary Table S13).

The $C_{\text {exhaust }}$ value of glycerol when using IT2.0a ("IT2.0a with person") was higher than that in the presence of people only ("With person"; $p=0.0131$ ) (Supplementary Tables S14). Statistical analysis could not be performed by comparing "IT2.0a with person" and "With person" using the $C_{\text {exhaust }}$ values of acrylonitrile, benzene, toluene, RSP, FPM, and propylene glycol. However, the $C_{\text {exhaust }}$ ("With person") values of acrylonitrile and benzene were $\angle \mathrm{LOD}$, while their $C_{\text {exhaust }}$ ("IT2.0a with person") values were detected ( $\left.<L O Q\right)$. The $C_{\text {exhaust }}$ ("With person") values of toluene, RSP, FPM, and propylene glycol were detected (median or $<$ LOQ), while their $C_{\text {exhaust }}$ ("IT2.0a with person") values were quantified (95\% Cl given). As acrylonitrile, benzene, and toluene were not detected by mainstream emission analysis (Supplementary Tables S4 and S14), their results were not attributed to actual concentration increases, but factors other than product use. As RSP had a large value $\left(0.393 \pm 0.302 \mathrm{mg} / \mathrm{m}^{3}\right) \mathrm{com}$ pared with the quantitative values of other dust analyzers (piezo, $<0.01 \mathrm{mg} / \mathrm{m}^{3}$; light scattering, $2.79 \pm 1.14 \mu \mathrm{g} / \mathrm{m}^{3}$ ), it was considered necessary to reexamine the analytical system. The $C_{\text {exhaust }}$ value of FPM $\left(0.0829 \pm 0.0205 \mu \mathrm{g} / \mathrm{m}^{3}\right)$ was derived from the air supply, because the $C_{B G}$ value of FPM was similar $\left(0.0776 \pm 0.0215 \mu \mathrm{g} / \mathrm{m}^{3}\right)$. All other constituents resulted in no actual increase in indoor air concentration. As a result, substantial concentration increases due to product use were observed for two constituents, namely, propylene glycol and glycerol (Table 3 and Supplementary Table S14).

The $C_{\text {exhaust }}$ value of acetaldehyde when using DT2.2a ("DT2.2a with person") was higher than that in the presence of people only ("With person"; $p=0.0334$ ) (Supplementary Table S15). Statistical analysis could not be performed by comparing "DT2.2a with person" and "With person" using the $C_{\text {exhaust }}$ values of acrylonitrile, pyridine, FPM (expressed as scopoletin equivalents), and propylene glycol. However, the $C_{\text {exhaust }}$ ("With person") value of acrylonitrile was $\angle L O D$, while its $C_{\text {exhaust }}$ ("DT2.2a with person") value was detected ( $<\mathrm{LOQ}$ ). The $C_{\text {exhaust }}$ ("With person") values of pyridine, FPM, and propylene glycol were $<\mathrm{LOQ}$, while their $C_{\text {exhaust }}$ ("DT2.2a with person") values were quantified. As pyridine was detected by mainstream emission analysis (Supplementary Tables S5 and S15), its increased concentration was attributed to product use. In contrast, as acrylonitrile was not detected by mainstream emission analysis (Supplementary Tables S5 and S15), its results were not attributed to an increase in actual concentration, but factors other than product use. The $C_{\text {exhaust }}$ value of FPM $\left(0.0789 \pm 0.0161 \mu \mathrm{g} / \mathrm{m}^{3}\right)$ was considered to be derived from the air supply, because it was similar to the $C_{B G}$ value $\left(0.0743 \pm 0.0167 \mu \mathrm{g} / \mathrm{m}^{3}\right)$. All other constituents resulted in no actual increase in indoor air concentration. Accordingly, a substantial concentration increase due to product use was observed for three constituents, namely, acetaldehyde, pyridine, and propylene glycol (Table 3 and Supplementary Table S15).

Comparing the $\mathrm{C}_{\text {exhaust }}$ values of "Cigarette with person" and "With person" showed an increase in constituent concentrations, except for benzo[a]pyrene, mercury, chromium, nickel, beryllium, arsenic, and $\mathrm{CO}_{2}$, which was attributed to product use. Therefore, a substantial concentration increase due to cigarette smoke was observed for 41 constituents (Table 3 and Supplementary Table S16). 
Table 3 Summary of indoor air concentration $\left(C_{\text {exhaust }}\right)$ under simulated "Residential" conditions

\begin{tabular}{|c|c|c|c|c|c|c|}
\hline \multirow[t]{2}{*}{ Constituent } & \multirow[t]{2}{*}{ Unit } & With person & IT1.0a with person & IT2.0a with person & DT2.2a with person & Cigarette with person \\
\hline & & \multicolumn{5}{|c|}{ Mean indoor air concertation $\mathrm{C}_{\text {exhaust }} \pm 95 \% \mathrm{Cl}$ (Median) } \\
\hline \multicolumn{7}{|l|}{ TSNA } \\
\hline NNN & $\left(\mathrm{ng} / \mathrm{m}^{3}\right)$ & $<$ LOD & $<$ LOD & $<$ LOD & $<$ LOD & $<\mathrm{LOQ}^{* *}$ \\
\hline NAT & $\left(\mathrm{ng} / \mathrm{m}^{3}\right)$ & $<$ LOD & $<$ LOD & $<$ LOD & $<$ LOD & $2.46 \pm 0.20^{* *}$ \\
\hline$N A B$ & $\left(\mathrm{ng} / \mathrm{m}^{3}\right)$ & $<L O D$ & $<L O D$ & $<L O D$ & $<$ LOD & $0.970 \pm 0.117^{* *}$ \\
\hline NNK & $\left(\mathrm{ng} / \mathrm{m}^{3}\right)$ & $<$ LOD & $<$ LOD & $<$ LOD & $<$ LOD & $18.3 \pm 5.0^{* *}$ \\
\hline \multicolumn{7}{|l|}{ Carbonyl } \\
\hline Formaldehyde & $\left(\mu \mathrm{g} / \mathrm{m}^{3}\right)$ & $8.38 \pm 0.71$ & $8.45 \pm 0.51$ & $9.49 \pm 1.09$ & $8.69 \pm 0.58$ & $72.0 \pm 3.3^{* *}$ \\
\hline Acetaldehyde & $\left(\mu \mathrm{g} / \mathrm{m}^{3}\right)$ & $5.30 \pm 0.46$ & $5.50 \pm 0.21$ & $7.61 \pm 1.62$ & $9.70 \pm 1.53^{* *}$ & $92.5 \pm 16.7^{* *}$ \\
\hline Acetone & $\left(\mu \mathrm{g} / \mathrm{m}^{3}\right)$ & $43.1 \pm 5.4$ & $43.3 \pm 2.0$ & $45.9 \pm 8.3$ & $45.0 \pm 4.5$ & $527 \pm 107^{* *}$ \\
\hline Acrolein & $\left(\mu \mathrm{g} / \mathrm{m}^{3}\right)$ & $0.0922 \pm 0.0105$ & $0.102 \pm 0.026$ & $0.127 \pm 0.049$ & $0.120 \pm 0.011$ & $0.842 \pm 0.0150^{* *}$ \\
\hline Propionaldehyde & $\left(\mu \mathrm{g} / \mathrm{m}^{3}\right)$ & $0.820 \pm 0.106$ & $0.839 \pm 0.048$ & $1.05 \pm 0.22$ & $1.10 \pm 0.10$ & $10.9 \pm 1.4^{* *}$ \\
\hline Crotonaldehyde & $\left(\mu \mathrm{g} / \mathrm{m}^{3}\right)$ & $0.0507 \pm 0.0011$ & $0.0519 \pm 0.0033$ & $0.0591 \pm 0.0090$ & $0.0605 \pm 0.0098$ & $0.681 \pm 0.075^{* *}$ \\
\hline MEK & $\left(\mu \mathrm{g} / \mathrm{m}^{3}\right)$ & $3.09 \pm 0.46$ & $3.90 \pm 1.09$ & $4.08 \pm 1.04$ & $3.65 \pm 0.57$ & $37.4 \pm 5.4^{* *}$ \\
\hline n-Butyraldehyde & $\left(\mu \mathrm{g} / \mathrm{m}^{3}\right)$ & $1.11 \pm 0.15$ & $0.982 \pm 0.040$ & $1.08 \pm 0.09$ & $1.35 \pm 0.12$ & $19.7 \pm 4.0^{* *}$ \\
\hline \multicolumn{7}{|l|}{ VOC } \\
\hline 1,3-Butadiene & $\left(\mu \mathrm{g} / \mathrm{m}^{3}\right)$ & $3.96 \pm 1.18$ & $<\mathrm{LOQ}$ & $<\mathrm{LOQ}$ & $<\mathrm{LOQ}$ & $62.1 \pm 4.4^{* *}$ \\
\hline Isoprene & $\left(\mu \mathrm{g} / \mathrm{m}^{3}\right)$ & $6.41 \pm 0.67$ & $6.78 \pm 0.64$ & $7.65 \pm 1.41$ & $7.29 \pm 0.47$ & $151.6 \pm 6.7^{* *}$ \\
\hline Acrylonitrile & $\left(\mu \mathrm{g} / \mathrm{m}^{3}\right)$ & $<$ LOD & $<$ LOD & $<\mathrm{LOQ}^{*}$ & $<\mathrm{LOQ}^{*}$ & $5.27 \pm 0.59^{* *}$ \\
\hline Benzene & $\left(\mu \mathrm{g} / \mathrm{m}^{3}\right)$ & $<$ LOD & $<$ LOD & $<\mathrm{LOQ}^{*}$ & $<\mathrm{LOQ}$ & $15.3 \pm 0.6^{* *}$ \\
\hline Toluene & $\left(\mu \mathrm{g} / \mathrm{m}^{3}\right)$ & $(2.30)$ & $(2.62)$ & $4.71 \pm 2.20^{*}$ & $3.76 \pm 0.84$ & $30.7 \pm 1.2^{* *}$ \\
\hline Pyridine & $\left(\mu \mathrm{g} / \mathrm{m}^{3}\right)$ & $<\mathrm{LOQ}$ & $<L O Q$ & $<\mathrm{LOQ}$ & $1.18 \pm 0.15^{* *}$ & $9.40 \pm 1.07^{* *}$ \\
\hline Styrene & $\left(\mu \mathrm{g} / \mathrm{m}^{3}\right)$ & $<\mathrm{LOQ}$ & $<\mathrm{LOQ}$ & $<\mathrm{LOQ}$ & $<\mathrm{LOQ}$ & $5.11 \pm 0.23^{* *}$ \\
\hline \multicolumn{7}{|l|}{ TVOC } \\
\hline TVOC & $\left(\mu \mathrm{g} / \mathrm{m}^{3}\right)$ & $71.7 \pm 27.3$ & $107 \pm 26$ & $124 \pm 31$ & $93.5 \pm 29.4$ & $420 \pm 50^{* *}$ \\
\hline \multicolumn{7}{|l|}{$P A H$} \\
\hline Benz [a] pyrene & $\left(\mathrm{ng} / \mathrm{m}^{3}\right)$ & $<$ LOD & $<$ LOD & $<$ LOD & $<$ LOD & $<$ LOD \\
\hline \multicolumn{7}{|l|}{$P A A$} \\
\hline 1-Aminonaphthalene & $\left(\mathrm{ng} / \mathrm{m}^{3}\right)$ & $<\mathrm{LOQ}$ & $<\mathrm{LOQ}$ & $<\mathrm{LOD}$ & $<\mathrm{LOQ}$ & $9.62 \pm 0.66^{* *}$ \\
\hline 2-Aminonaphthalene & $\left(\mathrm{ng} / \mathrm{m}^{3}\right)$ & $<\mathrm{LOQ}$ & $<\mathrm{LOQ}$ & $<\mathrm{LOQ}$ & $<\mathrm{LOQ}$ & $14.9 \pm 0.8^{* *}$ \\
\hline 3-Aminobiphenyl & $\left(\mathrm{ng} / \mathrm{m}^{3}\right)$ & $<\mathrm{LOQ}$ & $<\mathrm{LOQ}$ & $<\mathrm{LOQ}$ & $<\mathrm{LOQ}$ & $5.16 \pm 0.21^{* *}$ \\
\hline 4-Aminobiphenyl & $\left(\mathrm{ng} / \mathrm{m}^{3}\right)$ & $<$ LOQ & $<$ LOQ & $<\mathrm{LOQ}$ & $<$ LOQ & $3.87 \pm 0.13^{* *}$ \\
\hline \multicolumn{7}{|l|}{ Mercury } \\
\hline $\mathrm{Hg}$ & $\left(\mathrm{ng} / \mathrm{m}^{3}\right)$ & $<\mathrm{LOQ}$ & $<\mathrm{LOQ}$ & $<\mathrm{LOQ}$ & $<\mathrm{LOQ}$ & $<\mathrm{LOQ}$ \\
\hline \multicolumn{7}{|l|}{ Metal } \\
\hline Lead $(\mathrm{Pb})$ & $\left(\mathrm{ng} / \mathrm{m}^{3}\right)$ & $<\mathrm{LOQ}$ & $<\mathrm{LOQ}$ & $<\mathrm{LOQ}$ & $<\mathrm{LOQ}$ & $10.9 \pm 2.6^{* *}$ \\
\hline Cadmium (Cd) & $\left(\mathrm{ng} / \mathrm{m}^{3}\right)$ & $<$ LOD & $<$ LOD & $<$ LOD & $<$ LOD & $16.1 \pm 1.1^{* *}$ \\
\hline Chromium (Cr) & $\left(\mathrm{ng} / \mathrm{m}^{3}\right)$ & $<$ LOD & $<$ LOD & $<$ LOD & $<$ LOD & $<$ LOD \\
\hline Nickel (Ni) & $\left(\mathrm{ng} / \mathrm{m}^{3}\right)$ & $<$ LOD & $<$ LOD & $<$ LOD & $<$ LOD & $<$ LOD \\
\hline Beryllium (Be) & $\left(\mathrm{ng} / \mathrm{m}^{3}\right)$ & $<$ LOD & $<$ LOD & $<$ LOD & $<$ LOD & $<$ LOD \\
\hline Arsenic (As) & $\left(\mathrm{ng} / \mathrm{m}^{3}\right)$ & $<$ LOD & $<$ LOD & $<$ LOD & $<$ LOD & $<$ LOD \\
\hline \multicolumn{7}{|l|}{$E T S-V$} \\
\hline Nicotine & $\left(\mu \mathrm{g} / \mathrm{m}^{3}\right)$ & $0.935 \pm 0.514$ & $1.49 \pm 0.57$ & $1.47 \pm 0.60$ & $1.95 \pm 0.60$ & $47.0 \pm 6.8^{* *}$ \\
\hline 3-ethenylprydine & $\left(\mu \mathrm{g} / \mathrm{m}^{3}\right)$ & $0.0509 \pm 0.0081$ & $0.0571 \pm 0.0050$ & $(0.0363)$ & $0.0515 \pm 0.0101$ & $13.7 \pm 1.3^{* *}$ \\
\hline \multicolumn{7}{|l|}{$E T S-P$} \\
\hline RSP & $\left(\mathrm{mg} / \mathrm{m}^{3}\right)$ & $<\mathrm{LOQ}$ & $0.383 \pm 0.064^{*}$ & $0.393 \pm 0.302^{*}$ & $<\mathrm{LOQ}$ & $0.821 \pm 0.132^{* *}$ \\
\hline UVPM (THBP) & $\left(\mu \mathrm{g} / \mathrm{m}^{3}\right)$ & $<\mathrm{LOQ}$ & $<$ LOD & $<\mathrm{LOQ}$ & $<\mathrm{LOQ}$ & $69.9 \pm 14.0^{* *}$ \\
\hline FPM (Scopoletin) & $\left(\mu \mathrm{g} / \mathrm{m}^{3}\right)$ & $<\mathrm{LOQ}$ & $0.0508 \pm 0.0034^{*}$ & $0.0829 \pm 0.0205^{*}$ & $0.0789 \pm 0.0161^{*}$ & $16.9 \pm 2.5^{* *}$ \\
\hline Solanesol & $\left(\mu \mathrm{g} / \mathrm{m}^{3}\right)$ & $<$ LOD & $<\mathrm{LOD}$ & $<$ LOD & $<$ LOD & $14.8 \pm 2.2^{* *}$ \\
\hline
\end{tabular}


Table 3 (continued)

\begin{tabular}{|c|c|c|c|c|c|c|}
\hline \multirow[t]{2}{*}{ Constituent } & \multirow[t]{2}{*}{ Unit } & With person & IT1.0a with person & IT2.0a with person & DT2.2a with person & Cigarette with person \\
\hline & & \multicolumn{5}{|c|}{ Mean indoor air concertation $C_{\text {exhaust }} \pm 95 \% \mathrm{Cl}$ (Median) } \\
\hline \multicolumn{7}{|l|}{$P G / G$} \\
\hline Propylene glycol & $\left(\mu \mathrm{g} / \mathrm{m}^{3}\right)$ & $<\mathrm{LOQ}$ & $60.1 \pm 7.3^{* *}$ & $84.8 \pm 26.3^{* *}$ & $20.5 \pm 6.0^{* *}$ & $27.5 \pm 1.4^{* *}$ \\
\hline Glycerol & $\left(\mu \mathrm{g} / \mathrm{m}^{3}\right)$ & $13.6 \pm 1.7$ & $34.0 \pm 6.7$ & $50.6 \pm 7.4^{* *}$ & $29.2 \pm 7.5$ & $20.3 \pm 1.5^{* *}$ \\
\hline \multicolumn{7}{|l|}{$\mathrm{CO} / \mathrm{CO}_{2}$} \\
\hline $\mathrm{CO}$ & (ppm) & $0.360 \pm 0.049$ & $0.321 \pm 0.028$ & $0.393 \pm 0.077$ & $0.394 \pm 0.030$ & $2.65 \pm 0.05^{* *}$ \\
\hline $\mathrm{CO}_{2}$ & (ppm) & $1040 \pm 57$ & $1110 \pm 73$ & $1070 \pm 52$ & $1120 \pm 76$ & $1100 \pm 60$ \\
\hline \multicolumn{7}{|l|}{ SPM } \\
\hline Piezobalance & $\left(\mathrm{mg} / \mathrm{m}^{3}\right)$ & $<$ LOD & $<$ LOD & $<$ LOD & $<$ LOD & $0.354 \pm 0.030^{* *}$ \\
\hline Light scattering & $\left(\mu \mathrm{g} / \mathrm{m}^{3}\right)$ & $1.67 \pm 0.88$ & $1.17 \pm 0.40$ & $2.79 \pm 1.14$ & $4.12 \pm 1.20$ & $328 \pm 37^{* *}$ \\
\hline \multicolumn{7}{|l|}{ Ammonia } \\
\hline $\mathrm{NH}_{3}$ & (ppb) & $30.7 \pm 8.6$ & $40.6 \pm 8.7$ & $28.8 \pm 9.6$ & $36.7 \pm 12.3$ & $216 \pm 22^{* *}$ \\
\hline \multicolumn{7}{|l|}{$N O_{X}$} \\
\hline NO & (ppb) & $2.51 \pm 0.56$ & $1.92 \pm 0.17$ & $5.03 \pm 3.24$ & $2.30 \pm 0.18$ & $33.0 \pm 3.6^{* *}$ \\
\hline $\mathrm{NO}_{2}$ & (ppb) & $7.31 \pm 1.63$ & $7.67 \pm 1.68$ & $14.6 \pm 7.2$ & $11.9 \pm 3.0$ & $22.4 \pm 3.4^{* *}$ \\
\hline $\mathrm{NO}+\mathrm{NO}_{2}$ & (ppb) & $9.11 \pm 2.04$ & $9.44 \pm 1.79$ & $21.0 \pm 11.7$ & $14.3 \pm 3.3$ & $42.5 \pm 8.9^{* *}$ \\
\hline
\end{tabular}

The constituents evaluated as "Status1" displayed in bold

**Status1, "Actual indoor air concentration increase ("> With person")", shown in Sect. 2.7

*Status2, "Not actual indoor air concentration increase", shown in Sect. 2.7

\section{Discussion}

\subsection{Evaluation of indoor air quality}

In this study, the indoor air concentrations when using each product were compared with that when people only were presence, and the constituents were evaluated into three statuses (shown in Sect. 2.7). The increases of the indoor air concentration were observed in the constituents evaluated as Status2. However, the results were considered to be not attributed to actual indoor air concentration increases, but factors other than product use because the constituents were not detected by mainstream emission analysis.

When using IT1.0a under "Restaurant" condition, 1,3-butadiene, acrylonitrile, benzene, and pyridine were evaluated as Status2. The $C_{\text {exhaust }}$ ("IT1.0a with person") values of 1,3-butadiene, benzene, and pyridine $(<\mathrm{LOQ},<\mathrm{LOQ}$ and $1.37 \pm 0.09 \mu \mathrm{g} / \mathrm{m}^{3}$, respectively) were considered to be derived from the air supply, because the $\mathrm{C}_{\mathrm{BG}}$ ("IT1.0a with person") values were similar $(<L O Q,<L O Q$ and $1.12 \pm 0.10 \mu \mathrm{g} / \mathrm{m}^{3}$, respectively) (Supplementary Table S7). The $C_{\text {exhaust }}$ ("IT1.0a with person") values for each day of acrylonitrile were $<\mathrm{LOQ},<\mathrm{LOD},<\mathrm{LOQ}$ and $<\mathrm{LOD}$, respectively (the calculated indoor air concentration was $<L O Q$ ), on the other hands, the $C_{\text {exhaust }}$ ("With person") values were $\angle \mathrm{LOQ}, \angle \mathrm{LOD}, \angle \mathrm{LOD}$ and $\angle \mathrm{LOD}$, respectively (the calculated indoor air concentration was $<$ LOD) (Supplementary Table S7). This difference of the indoor air concentrations ( $<$ LOQ vs. $<$ LOD) was caused by our calculation method using four data points, and it is considered necessary to increase the number of replicated times for more clear evaluation.

When using IT2.0a under "Restaurant" condition, propionaldehyde, 1,3-butadiene, acrylonitrile, benzene, pyridine, and 1-aminonaphthalene were evaluated as Status2. The factor that the indoor air concentrations of 1,3-butadiene, acrylonitrile, benzene, pyridine, and 1-aminonaphthalene were increased was the same case of the $C_{\text {exhaust }}$ ("IT1.0a with person") values of acrylonitrile under "Restaurant" condition (Supplementary Table S7). The result that the indoor air concentration of propionaldehyde was increased was not attributed to actual indoor air concentration increase in this study. However, further investigation is needed to reveal whether the indoor air concentration of propionaldehyde increases or not.

When using DT2.2a under "Restaurant" condition, crotonaldehyde, MEK, 1,3-butadiene, and acrylonitrile were evaluated as Status2. The $C_{\text {exhaust }}$ ("DT2.2a with person") value of acrylonitrile $(<\mathrm{LOQ})$ was considered to be derived from the air supply, because the $C_{B G}$ ("DT2.2a with person") value was similar (<LOQ) (Supplementary Table S7). The factor that the indoor air concentration of 1,3-butadiene was increased was the same case of the $C_{\text {exhaust }}$ ("IT1.0a with person") values of acrylonitrile under "Restaurant" condition (Supplementary Table S7). The results that the indoor air concentrations of crotonaldehyde and MEK were increased were not attributed to actual indoor air 
concentration increase in this study. However, further investigation is also needed to reveal whether the indoor air concentrations increase or not.

When using IT2.0a under "Residential" condition, acrylonitrile, benzene, and toluene were evaluated as Status 2 . The $C_{\text {exhaust }}$ ("IT2.0a with person") values of acrylonitrile and benzene ( $<\mathrm{LOQ}$ and $<\mathrm{LOQ}$, respectively) were considered to be derived from the air supply, because the $C_{B G}$ ("IT2.0a with person") values were similar (<LOQ and $<L O Q$, respectively) (Supplementary Table S8). The $C_{\text {exhaust }}$ ("IT2.0a with person") values for each day of toluene were $1.49,5.45,10.6$ and $1.25 \mu \mathrm{g} / \mathrm{m}^{3}$, respectively and the $C_{B G}$ ("IT2.0a with person") values were $<L O Q$, 4.14, $8.84 \mu \mathrm{g} / \mathrm{m}^{3}$ and $<\mathrm{LOQ}$, respectively. In addition, the $C_{\text {exhaust }}$ ("With person") values for each day of toluene were $<\mathrm{LOQ}$, $3.90,4.20 \mu \mathrm{g} / \mathrm{m}^{3}$ and $<\mathrm{LOQ}$, respectively and the $\mathrm{C}_{\mathrm{BG}}$ ("With person") values were $<L O Q, 3.01,2.78 \mu \mathrm{g} / \mathrm{m}^{3}$ and $<L O Q$, respectively (Supplementary Table S8). It was considered that the $C_{\text {exhaust }}$ values were affected by the $C_{B G}$ values and the $C_{\text {exhaust }}$ ("IT2.0a with person") value was not attributed to actual indoor air concentration increase. It is necessary to avoid deriving from the air supply for more clear evaluation.

When using DT2.2a under "Residential" condition, acrylonitrile was evaluated as Status2. The $C_{\text {exhaust }}$ ("DT2.2a with person") value of acrylonitrile $(<\mathrm{LOQ})$ was considered to be derived from the air supply, because it was similar to the $C_{B G}$ ("DT2.2a with person") value (<LOQ) (Supplementary Table $\mathrm{S} 8$ ).

\subsection{Comparison of operating environmental condition}

In this study, an environmentally controlled chamber was used and two simulated environments ("Restaurant" and "Residential" conditions) were examined. When comparing results from different simulated environments, it is important to consider the experimental setup of the test conditions. Numerous factors, including ventilation flow rate, total number of cigarettes consumed, and emission yields, must be considered. The impact of cigarette on IAQ can be normalized using ventilated air volume per cigarette $\left(\mathrm{m}^{3} /\right.$ cigarette) because the constituent concentrations are the same when the number of cigarettes burned in the total volume of ventilated air is the same. Previously reported environmental simulations with ventilated air volumes closest to that used in this study ("Residential" at $9.00 \mathrm{~m}^{3}$ /cigarette) were "Residential category III" at 6.17 $\mathrm{m}^{3} /$ cigarette [9] and "office" at $10.2 \mathrm{~m}^{3} /$ cigarette [11]. These studies used the same types of cigarette $(6$ or $7 \mathrm{mg}$ tar/ cigarette) as this study (6 mg tar/cigarette; Supplementary Table S17).
The results reported by Mitova et al. (2019) were broadly aligned with the "Residential" conditions in this study. Considering the 1.46 -fold difference in ventilated air volume per cigarette $\left(9.00 \mathrm{~m}^{3} /\right.$ cigarette vs. $6.17 \mathrm{~m}^{3} /$ cigarette), most of the observed concentrations of vapor matter were same, except for NNN, NNK, acrolein, crotonaldehyde, 1,3-butadiene and glycerol. However, the concentrations of particulate matter, such as UVPM, FPM, and solanesol, were same reported by Mitova et al. (2019). These might have been influenced by the way people puffed and breathed in (deep or shallow inhalation) because the vapor phase might be more readily absorbed in the lungs than particulate matter. Furthermore, we consider that in the case of our test design this time, since it is not reaching steady state, the differences in air change rates and test time also affected the concentration. In contrast, the results of cigarette use in an "office" environment [11] corresponded well with the results of "Residential" conditions in this study. This good agreement with two previous chamber studies clearly indicated that the results of the present study were representative.

\subsection{Design of environmental control test room}

In research on environmental tobacco aerosol using heating tobacco systems, IAQ evaluation is difficult owing to the low amount of tobacco aerosol generated and its low indoor concentration.

This section describes the design of the environmental test room. The advantage of performing IAQ evaluation using an environmental chamber is that not only various environmental scenarios specified by the standard (e.g., the European standard EN 15,251 [21], ASHRAE 62-1 and 62-2 [29, 30]), but also real environments, can be simulated. Previous reports have shown good correlation between chamber-based measurements and measurements in real environments [10]. It is also possible to minimize additional pollution sources of air constituents in the chamber by passing the air supplied to the room through a chemical filter (HEPA was used in this study), which is advantageous for conducting the evaluation.

Both temperature and relative humidity were monitored. The temperature and relative humidity inside the chamber throughout this study were $24.6 \pm 1.1{ }^{\circ} \mathrm{C}$ and $32.6 \% \pm 6.2 \%$, respectively ( \pm standard deviation). Although the temperature of this study was within that of a real-world condition, 17 to $28^{\circ} \mathrm{C}$, as defined by the Ministry of Health, Labour and Welfare (MHLW) of Japan, the relative humidity was lower than that defined by the Ministry, $40 \%$ to $70 \%$ [31]. Therefore, it is necessary to conduct a future study in a chamber room that has controllable temperature and relative humidity to maintain these parameters at appropriate values. 
In this study design, under "Restaurant" conditions, a ventilation volume (ventilation frequency) based on BS EN 15251:2007 [21] was adopted. Regarding the number of people present, the influence of chemical constituents generated by the human body were removed as much as possible, and the number of cigarettes smoked by the test collaborators was set to not increase excessively. Regarding smoking rate, $20 \%$, as stated in the standard, was assumed to be lower than that in the actual environment, and was therefore changed to $100 \%$ and installed to avoid underestimation. A smoking rate of $100 \%$ was also adopted in the trial design under "Residential" conditions. Although the standard is defined as to provide the ventilation air volume given to both each person and each area, to assume harsh conditions, the ventilation air volume given to each person was not provided, with only the air volume given to each area adopted. A test time of $1 \mathrm{~h}$ was adopted owing to the test room equipment (only one test room door was installed, no front room) and physical stress on the testing smokers. Other reports often use test times of $2 \mathrm{~h}$ or longer. When the air change rate is low, as found in the "Residential" conditions, it may take more time for the concentration of constituents to reach a steady state. Therefore, the effect of test time on IAQ evaluation is expected to be large. Further comparisons should be conducted for optimal IAQ evaluation.

\subsection{Analytical aspects}

In this study, chemical constituents were conducted according to international standards and regulations. The constituent yields in mainstream emissions from heating tobacco systems and cigarettes were essentially the same as those previously reported $[32,33]$.

IAQ evaluation focused on the following constituents: (1) 33 constituents for which in-house measurement methods have been established, based on 44 constituents recommended by the Canadian public health authorities according to health risk by prioritizing reducing their contents; (2) a part of heating tobacco system-specific constituents; (3) ETS markers; and (4) the indoor environment index. Accordingly, the number of constituents shown in this study was larger than in our previous report [10].

As low-concentration measurements are required for $I A Q$ evaluation, improvements for collection and instrumental analysis methods were examined. For TSNA and metals, a new in-house method was developed (Supplementary Tables S18-S21 for confirmation data of method application to IAQ analysis).

The analytical precision of measurements reported in this study was similar to that previously published [13,
32-34]. However, in both simulated environments, "Restaurant" and "Residential", RSP (part of ETS-P) showed a large value compared with the quantitative values of other dust analyzers (piezo and light scattering dust analyzer). The RSP data in this study showed very large differences between days (Supplementary Tables S7 and S8). As RSP is gravimetric particle matter measured by balances, it is considered necessary for re-examining the analytical system, including the working procedures.

\subsection{Standards and guidelines for air quality}

In this study, eleven constituents (NNN, NAT, NNK, acetaldehyde, propionaldehyde, $n$-butyraldehyde, benzene, pyridine, TVOC, PG, and G) showed a substantial increase in indoor air concentration when heating tobacco systems were used in the "Restaurant" and "Residential" simulated environments (Tables 2, 3, Supplementary Tables S9-S16).

The NNN, NAT, and NNK concentrations ( $\left.C_{\text {exhaust }}\right)$ measured using DT2.2a under "Restaurant" conditions were 2.85 (median) $\mathrm{ng} / \mathrm{m}^{3},<$ LOQ $\left(1.57 \mathrm{ng} / \mathrm{m}^{3}\right)$, and $<$ LOQ $\left(1.21 \mathrm{ng} / \mathrm{m}^{3}\right)$, respectively. Using cigarettes, these values were $3.43 \pm 0.32,2.70 \pm 0.372$, and $23.3 \pm 4.22 \mathrm{ng} / \mathrm{m}^{3}$, respectively. The indoor concentration of NNK was obviously lower than that of smoking, but NNN and NAT were around the $L O Q$ value, making proper evaluation impossible. TSNA, especially NNN and NNK, include harmful and potentially harmful constituents (HPHCs) on the U.S. Food and Drug Administration (FDA) list [35], and have a major health impact, making further investigation necessary.

The acetaldehyde concentrations $\left(C_{\text {exhaust }}\right)$ measured using DT2.2a under "Restaurant" and "Residential" conditions ( $10.4 \pm 1.1$ and $9.70 \pm 1.53 \mu \mathrm{g} / \mathrm{m}^{3}$, respectively) were below the chronic exposure $\left(140 \mu \mathrm{g} / \mathrm{m}^{3}\right)$ listed by the California Office of Environmental Health Hazard Assessment [36], the proposed exposure limit $\left(200 \mu \mathrm{g} / \mathrm{m}^{3}\right)$ of the European Commission [37], and the exposure limit (48 $\mu \mathrm{g} /$ $\mathrm{m}^{3}$ ) by the Ministry of Health Labour and Welfare (MHLW) of Japan [38]. The World Health Organization (WHO) [39] considers acetaldehyde to be a regulated candidate air pollutant.

The propionaldehyde concentrations $\left(C_{\text {exhaust }}\right)$ measured using DT2.2a under "Restaurant" conditions $\left(1.17 \pm 0.07 \mu \mathrm{g} / \mathrm{m}^{3}\right)$ was also well below the access acute exposure guideline level (AEGLs) values $\left(110 \mathrm{mg} / \mathrm{m}^{3}\right.$; AEGL-1 for $1 \mathrm{~h}$ ) listed by the United States Environmental Protection Agency [40].

The $n$-butyraldehyde concentrations $\left(C_{\text {exhaust }}\right)$ measured when using DT2.2a under "Restaurant" conditions $\left(2.08 \pm 0.30 \mu \mathrm{g} / \mathrm{m}^{3}\right)$ was also well below the workplace environmental exposure level $\left(75 \mathrm{mg} / \mathrm{m}^{3}\right)$ listed by the Occupational Alliance for Risk Science (OARS) [41]. 
The benzene concentration $\left(C_{\text {exhaust }}\right)$ measured using DT2.2a under "Restaurant" conditions (<LOQ (2.16) $\mu \mathrm{g} /$ $\left.\mathrm{m}^{3}\right)$ was also below the chronic exposure $\left(3 \mu \mathrm{g} / \mathrm{m}^{3}\right)$ listed by the California Office of Environmental Health Hazard Assessment [36] and the exposure limit $\left(5 \mu \mathrm{g} / \mathrm{m}^{3}\right)$ proposed by the European Commission [37].

The pyridine concentrations $\left(C_{\text {exhaust }}\right)$ measured using DT2.2a under "Restaurant" and "Residential" conditions $\left(1.59 \pm 0.14\right.$ and $1.18 \pm 0.15 \mu \mathrm{g} / \mathrm{m}^{3}$, respectively) were well below the recommended value $\left(16.1 \mathrm{mg} / \mathrm{m}^{3}\right)$ listed by the Scientific Committee on Occupational Exposure Limits (SCOEL) [42] and the permissible exposure limit (15 mg/ $\mathrm{m}^{3}$ ) listed by the Occupational Safety and Health Administration (OSHA) [43].

The TVOC concentrations $\left(C_{\text {exhaust }}\right)$ measured using IT1.0a and IT2.0a under "Restaurant" conditions (83.2 \pm 9.2 and $84.2 \pm 7.5 \mu \mathrm{g} / \mathrm{m}^{3}$, respectively) were below the provisional target value $\left(400 \mu \mathrm{g} / \mathrm{m}^{3}\right)$ listed by MHLW Japan [38]. In other countries, hundreds of target values are set.

The propylene glycol concentration $\left(C_{\text {exhaust }}\right)$ values measured using three heating tobacco systems under "Restaurant" and "Residential" conditions ranged from $29.9 \pm 7.7 \mu \mathrm{g} / \mathrm{m}^{3}$ to $106 \pm 34 \mu \mathrm{g} / \mathrm{m}^{3}$ and from $20.5 \pm 6.0 \mu \mathrm{g} /$ $\mathrm{m}^{3}$ to $84.8 \pm 26.3 \mu \mathrm{g} / \mathrm{m}^{3}$, respectively. Furthermore, the glycerol concentration ( $C_{\text {exhaust }}$ ) ranged from $37.3 \pm 6.9 \mu \mathrm{g} /$ $\mathrm{m}^{3}$ to $90.9 \pm 20.5 \mu \mathrm{g} / \mathrm{m}^{3}$ and from $29.2 \pm 7.5 \mu \mathrm{g} / \mathrm{m}^{3}$ to $50.6 \pm 7.4 \mu \mathrm{g} / \mathrm{m}^{3}$, respectively. These concentrations were well below the occupational guideline value for propylene glycol in air $\left(10 \mathrm{mg} / \mathrm{m}^{3}\right)$ listed by the American Industrial Hygiene Association (AlHA) [41] and the permissible exposure limit of glycerol (mist) $\left(5 \mathrm{mg} / \mathrm{m}^{3}\right)$ listed by the Occupational Safety and Health Administration (OSHA) [43].

\section{Conclusion}

The impact of using three types of heating tobacco systems on IAQ was simulated using an environmentally controlled chamber. IAQ was evaluated using 33 out of 42 constituents recommended by Canadian public health authorities for reductions in content owing to their health risk, environmental tobacco smoke markers, and indoor air quality markers (all 48 constituents). The simulated environmental conditions were denoted as "Restaurant" and "Residential". Under "Restaurant" conditions, the constituents for which the indoor air concentration was substantially increased compared with that in the presence of people only were TVOC and glycerol when using IT1.0a or IT2.0a, and NNN, NAT, NNK, acetaldehyde, propionaldehyde, $n$-butyraldehyde, benzene, pyridine, and glycerol when using DT2.2a. Furthermore, under "Residential" conditions, the constituents actually increased in concentration were propylene glycol when using IT1.0a, propylene glycol and glycerol when using IT2.0a, and acetaldehyde, pyridine, and propylene glycol when using DT2.2a. As the indoor air concentrations when using the three systems (IT1.0a, IT2.0a, and DT2.2a) were much lower than those with cigarette smoke, except for propylene glycol and glycerol, and below the exposure limits for compounds in air set by regulations, heating tobacco systems in appropriate indoor environments have less impacts compared to conventional cigarettes.

Acknowledgements The authors gratefully acknowledge Scientific Product Assessment Center (R\&D group, Japan Tobacco Inc.) for excellent technical assistance of chemical analysis.

Author contributions $\mathrm{YE}, \mathrm{RI}, \mathrm{KN}$ and $\mathrm{YF}$ analyzed and interpreted the data regarding the mainstream emissions and the indoor air quality. $\mathrm{KI}$ and $\mathrm{MK}$ performed the design, schedule and evaluation of this study, and were a major contributor in writing the manuscript. All authors read and approved the final manuscript.

Funding This study was supported by Japan Tobacco Inc. This research received no specific grant from any funding agency in the public, commercial, or not-for-profit sectors.

Availability of data and material All data generated or analyzed during this study are included in this published article and its supplementary information files.

\section{Declarations}

Conflict of interest The authors are employees of Japan Tobacco Inc., and they have no competing interests with respect to the research, authorship, and/or publication of this article.

Consent to participate The participates in this study were in-house volunteers from whom informed consent was obtained.

Open Access This article is licensed under a Creative Commons Attribution 4.0 International License, which permits use, sharing, adaptation, distribution and reproduction in any medium or format, as long as you give appropriate credit to the original author(s) and the source, provide a link to the Creative Commons licence, and indicate if changes were made. The images or other third party material in this article are included in the article's Creative Commons licence, unless indicated otherwise in a credit line to the material. If material is not included in the article's Creative Commons licence and your intended use is not permitted by statutory regulation or exceeds the permitted use, you will need to obtain permission directly from the copyright holder. To view a copy of this licence, visit http://creativecommons. org/licenses/by/4.0/.

\section{References}

1. Johnsson $T$, Tuomi $T$, Riuttala $H$, Hyvärinen $M$, Rothberg $M$, Reijula K (2006) Environmental tobacco smoke in finnish restaurants and bars before and after smoking restrictions were introduced. Ann Occup Hyg 50:331-341. https://doi.org/10. 1093/annhyg/mel011 
2. Bolte G, Heitmann D, Kiranoglu M, Schierl R, Diemer J, Koerner W, Fromme H (2008) Exposure to environmental tobacco smoke in German restaurants, pubs and discotheques. J Expo Sci Environ Epidemiol 18:262-271. https://doi.org/10.1038/sj.jes.7500590

3. Vainiotalo S, Väänänen V, Vaaranrinta R (2008) Measurement of 16 volatile organic compounds in restaurant air contaminated with environmental tobacco smoke. Environ Res 108:280-288. https://doi.org/10.1016/j.envres.2008.07.020

4. Protano C, Manigrasso M, Cammalleri V, Zoccai GBGB, Frati G, Avino P, Vitali M (2020) Impact of electronic alternatives to tobacco cigarettes on indoor air particular matter levels. Int J Environ Res Public Health 17:1-10. https://doi.org/10.3390/ijerp h17082947

5. Hirano T, Shobayashi T, Takei T, Wakao F (2020) Exposure assessment of environmental tobacco aerosol from heated tobacco products: nicotine and pm exposures under two limited conditions. Int J Environ Res Public Health 17:1-11. https://doi.org/ 10.3390/ijerph17228536

6. Schober W, Fembacher L, Frenzen A, Fromme H (2019) Passive exposure to pollutants from conventional cigarettes and new electronic smoking devices (IQOS, e-cigarette) in passenger cars. Int J Hyg Environ Health 222:486-493. https://doi.org/10. 1016/j.ijheh.2019.01.003

7. Kaunelienè V, Meišutovič-Akhtarieva $M$, Prasauskas T, Čiužas $D$, Krugly E, Keraitytè K, Martuzevičius D (2019) Impact of using a tobacco heating system (THS) on indoor air quality in a nightclub. Aerosol Air Qual Res 19:1961-1968. https://doi.org/10. 4209/aaqr.2019.04.0211

8. Meišutovič-Akhtarieva $M$, Prasauskas $T$, Čiužas $D$, Krugly $E$, Keraityte K, Martuzevičius D, Kaunelienè V (2019) Impacts of exhaled aerosol from the usage of the tobacco heating system to indoor air quality: a chamber study. Chemosphere 223:474482. https://doi.org/10.1016/j.chemosphere.2019.02.095

9. Mitova MI, Bielik N, Campelos PB, Cluse C, Goujon-Ginglinger CG, Jaquier A, Gomez Lueso M, Maeder S, Pitton C, Poget L et al (2019) Air quality assessment of the Tobacco Heating System 2.2 under simulated residential conditions. Air Qual Atmos Heal 12:807-823. https://doi.org/10.1007/s11869-019-00697-6

10. Ichitsubo $H$, Kotaki $M(2018)$ Indoor air quality (IAQ) evaluation of a Novel Tobacco Vapor (NTV) product. Regul Toxicol Pharmacol 92:278-294. https://doi.org/10.1016/j.yrtph.2017.12.017

11. Forster M, McAughey J, Prasad K, Mavropoulou E, Proctor C (2018) Assessment of tobacco heating product THP1.0. Part 4: characterisation of indoor air quality and odour. Regul Toxicol Pharmacol 93:34-51. https://doi.org/10.1016/j.yrtph.2017.09. 017

12. Gómez Lueso M, Mitova MI, Mottier N, Schaller M, Rotach M, Goujon-Ginglinger CG (2018) Development and validation of a method for quantification of two tobacco-specific nitrosamines in indoor air. J Chromatogr A 1580:90-99. https://doi.org/10. 1016/j.chroma.2018.10.037

13. Mitova MI, Campelos PB, Goujon-Ginglinger CG, Maeder S, Mottier N, Rouget EGR, Tharin M, Tricker AR (2016) Comparison of the impact of the Tobacco Heating System 2.2 and a cigarette on indoor air quality. Regul Toxicol Pharmacol 80:91-101. https:// doi.org/10.1016/j.yrtph.2016.06.005

14. Mitova MI, Cluse C, Correia D, Goujon-ginglinger CG, Kleinhans S, Poget L, Sendyk SS (2021) Comprehensive air quality assessment of the tobacco heating System 2.2 under simulated indoor environments. Atmosphere. https://doi.org/10.3390/atmos 12080989

15. Meišutovič-Akhtarieva $M$, Prasauskas $T$, Čiužas $D$, Kaunelienè $V$, Martuzevičius D (2021) The dynamics of exhaled aerosol following the usage of heated tobacco product, electronic cigarette, and conventional cigarette. Aerosol Air Qual Res 21:200653. https://doi.org/10.4209/aaqr.200653
16. Caraway JW, Jin T, Schmidt E, Nelson PR (2021) A Single-center evaluation of environmental emissions from ENDS and combustible cigarettes. Beitrage zur Tab Int Contrib Tob Res 30:3-24. https://doi.org/10.2478/cttr-2021-0002

17. Health Canada Tobacco Reporting Regulations (2000)

18. International Organization for Standardization standard Routine Analytiacal Cigarette-smoking Machine - Definitions and Standard Conditions. 61010-1 @ lec2001, 2006, 13 (2012)

19. International Organization for Standardization standard Tobacco and Tobacco Products - Atmosphere for Conditioning and Testing. 61010-1 ( lec2001, 2006, 13 (1999)

20. International Organization for Standardization standard Cigarettes: Determination of Total and Nicotine-free Dry Particulate Matter Using a Routine Analytical Smoking Machine. 61010-1 (c) lec2001, 2006, 13 (2000)

21. European committee for standardization. Indoor Environmental Input Parameters for Design and Assessment of Energy Performance of Buildings Addressing Indoor Air Quality, Thermal Environment, Lighting and Acoustics. EN 15251 (2007)

22. Ministry of Health Labour and Welfare (MHLW) Japan Heisei 11-12 Nendo Tabakoen No Seibun Bunseki Nituite (Translating to English: Constituent Analysis of Tobacco Smoke in Years from 1999 to 2000). (In Japanese) (2001). https://www.mhlw.go.jp/ topics/tobacco/houkoku/seibun.html. Accessed 30 August 2021

23. International Organization for Standardization standard Indoor air-Part 3:Determination of formaldehyde and other carbonyl compounds in indoor air and test chamber air-Active sampling method. 61010-1 @ lec2001, 2006, 13 (2011)

24. International Organization for Standardization standard Indoor air-Part 6:Determination of volatile organic compounds in indoor and test chamber air by active sampling on Tenax TA sorbent, thermal desorption and gas chromatography using MS or MS-FID. 2011 (2011)

25. International Organization for Standardization standard Indoor, ambient and workplace air-Sampling and analysis of volatile organic compounds by sorbent tube/thermal desorption/capillary gas chromatography_Part 1:Pumped sampling. 61010-1 (c) lec2001, 2006, 13 (2000)

26. International Organization for Standardization standard Environmental tobacco smoke-Determination of vapour phase nicotine and 3-ethenylpyridine in air-Gas- chromatographic method. 61010-1 @ lec2001, 2006, 13 (2003)

27. International Organization for Standardization standard Environmental tobacco smoke-Estimation of its contribution to respirable suspended particles-Determination of particulate matter by ultraviolet absorbance and by fluorescence. 61010-1 (c) lec2001, 2006, 13 (2001)

28. International Organization for Standardization standard Environmental tobacco smoke-Estimation of its contribution to respirable suspended particles-Method based on solanesol. 2003 (2003)

29. American Society of Heating Refrigerating and Air-Conditioning Engineers (ASHRAE). Ventilation for Acceptable Indoor Air Quality. ANSI/ASHRAE Stand. 62.1-2016 (2016)

30. American Society of Heating Refrigerating and Air-Conditioning Engineers (ASHRAE). Ventilation and Acceptable Indoor Air Quality in Residential Buildings. ANSI/ASHRAE Stand. 62.2-2016 (2016).

31. Ministry of Health Labour and Welfare (MHLW) Japan Act on Maintenance of Sanitation in Buildings, Act No. 69 of 2014 (Revision of Act No. 20 of 1970). (In Japanese). (2014). http:// www.mhlw.go.jp/bunya/kenkou/seikatsu-eisei10/. Accessed 30 August 2021

32. Margham J, Mcadam K, Forster M, Liu C, Wright C, Mariner D, Proctor C (2016) Chemical composition of aerosol from an 
E-cigarette: a quantitative comparison with cigarette smoke. Chem Res Texicol. https://doi.org/10.1021/acs.chemrestox. $6 \mathrm{~b} 00188$

33. Schaller JP, Keller D, Poget $L$, Pratte $P$, Kaelin $E$, McHugh $D$, Cudazzo G, Smart D, Tricker AR, Gautier L et al (2016) Evaluation of the tobacco heating system 2.2: part 2: chemical composition, genotoxicity, cytotoxicity, and physical properties of the aerosol. Regul Toxicol Pharmacol 81:S27-S47. https://doi.org/10.1016/j. yrtph.2016.10.001

34. Tricker ARAR, Schorp MKMK, Urban HJH-J, Leyden D, Hagedorn HWH-W, Engl J, Urban M, Riedel K, Gilch G, Janket D et al (2009) Comparison of environmental tobacco smoke (ETS) concentrations generated by an electrically heated cigarette smoking system and a conventional cigarette. Inhal Toxicol 21:62-77. https://doi.org/10.1080/08958370802207334

35. Food and Drug Administration(FDA) Harmful and potentially harmful constituents in tobacco products and tobacco smoke; established list. 77, 20034-20037 (2012)

36. The Office of Environmental Health Hazard Assessment (OEHHA) OEHHA Acute, 8-hour and Chronic Reference Exposure Level (REL) Summary (2019). https://oehha.ca.gov/air/general-info/ oehha-acute-8-hour-and-chronic-reference-exposure-level-relsummary/. Accessed 30 August 2021

37. Koistinen et al. (2005) INDEX Project - Critical Appraisal of the Setting and Implementation of Indoor Exposure Limits in the EU
38. Ministry of Health Labour and Welfare (MHLW) Japan Shitunai Noudo Shishinnchi Ichiran (Translating to English: Indoor concentration guideline value list). (In Japanese). http://www.nihs. go.jp/mhlw/chemical/situnai/hyou.html. Accessed 30 August 2021

39. World Health Organization (WHO) (2010) WHO guidelines for indoor air quality: selected pollutants. Encycl Food Heal. https:// doi.org/10.1016/B978-0-12-384947-2.00550-X

40. United States Environmental Protection Agency Propionaldehyde AEGL Technical Support Document (2009)

41. Occupational Alliance for Risk Science (OARS) Workplace Environmental Exposure Levels. https://tera.org/OARS/. Accessed 30 August 2021

42. European Commission Recommendation from the Scientific Committee on Occupational Exposure Limits for pyridine, $\mathrm{pp}$ $1-28$ (2004)

43. Occupational Safety and Health Administration (OSHA) OSHA Occupational Chemical Database/Report Page of GLYCERINE(MIST). https://www.osha.gov/chemicaldata/416. Accessed 30 August 2021

Publisher's Note Springer Nature remains neutral with regard to jurisdictional claims in published maps and institutional affiliations. 